\title{
Microbiome First Approaches to Rescue Public Health and Reduce Human Suffering
}

\author{
Rodney R. Dietert ${ }^{*}$ \\ 1 Department of Microbiology and Immunology, Cornell University, Ithaca, NY 14853 USA; rrd1@cor- \\ nelll.edu \\ * Correspondence: rrd1@cornell.edu
}

\begin{abstract}
The is a sequential article to an initial review suggesting that Microbiome First medical approaches to human health and wellness could both aid the fight against noncommunicable diseases and conditions (NCDs) and help to usher in sustainable healthcare. This current review article specifically focuses on public health programs and initiatives and what has been termed by medical journals as a catastrophic record of recent failures. Included in the review is a discussion of the four priority behavioral modifications (food choices, cessation of two drugs of abuse, and exercise) advocated by the World Health Organization as the way to stop the ongoing NCD epidemic. The lack of public health focus on the majority of cells and genes in the human superorganism, the microbiome, is highlighted as is the "regulatory gap" failure to protect humans, particularly the young, from a series of mass population toxic exposures (e.g., asbestos, trichloroethylene, dioxin, polychlorinated biphenyls, triclosan, bisphenol A and other plasticizers, polyfluorinated compounds, herbicides, food emulsifiers, high fructose corn syrup, certain nanoparticles, endocrine disruptors, obesogens). The combination of early life toxicity for the microbiome and connected human physiological systems (e.g., immune, neurological), plus a lack of attention to the importance of microbial rebiosis has facilitated rather than suppressed, the NCD epidemic. This review article concludes with a call to place the microbiome first and foremost in public health initiatives as a way to both rescue public health effectiveness and reduce the human suffering connected to co-morbid NCDs.
\end{abstract}

Keywords: microbiome; public health; chronic diseases; microimmunosome; eating disorders; subtance use disorder; commensals; pathobionts; sensory receptors; developmental programming

\section{Introduction}

While public health began life with great promise such as the impact of sanitation and clean water [1], it has been on a slippery slope of repeated failures particularly during the $21^{\text {st }}$ century [2-7]. This review article illustrates that: 1) lack of recognition of the fundamental nature of humans (superorganisms/holobionts), 2) a failure to include the vast majority of human genes in public health initiatives (i.e., the human microbiomes), 3) failure to account for the role of microbiome dysbiosis in the majority of human deaths (inflammation-driven noncommunicable diseases and conditions (NCDs)) and 4) failure to recognize and/or eliminate NCD-promoting food additives, chemicals, and drugs has completely undermined decades worth of public health programs. This article provides examples of recent public health failures that each impact the battle against the ongoing epidemic of chronic disorders also known as NCDs.

Importantly, the article suggests a way back to meaningful public health success by undertaking microbiome first approaches to attack the NCD epidemic. Three specific categories of microbiota impacting public health are introduced as examples of microbiome 
first approaches. The paper also discusses the critical need for public health effectiveness in both education and action if we are to achieve sustainable healthcare.

It is of note that I am not the only one to call for a complete overhaul of public health to one that embraces the human holobiont and prioritizes microbiome-based health solutions. In their paper "A Framework for Microbiome Science in Public Health," Wilkinson et al. [8] make a similar appeal. As will be described in the following section, public health initiatives in the past several decades have been nothing short of a catastrophe. This paper argues that the only way forward to meaningful, relevant, and effective public health is: 1) to give our majority microbial copartners their due, and 2) to recognize that the ability of "public" health to actually reduce the prevalence of chronic disease (versus the unfettered growth of NCDs) can only occur when microbes are managed for the greater good.

\section{Recent Failures of the Public Health Promise}

In a 2004 editorial in the medical journal The Lancet titled "The Catastrophic Failures of Public Health" [3], the editors castigated $21^{\text {st }}$ century public health institutions for their misdirected focus. The editorial pointed out that the real public health threat was not the more glamorous pandemics such as SARS or avian influenza. Instead, it was the simpler and less glamorous reality that more people are becoming obese and sedentary, and are "more prone to killer chronic illnesses, such as cardiovascular disease, stroke, cancer, and diabetes." As proof, the editorial went on to cite CDC statistics showing that human illness and death overwhelmingly occurred because of the NCDs and not the pandemics [3]. The Lancet's 2004 call for Public Health Institutions to focus on the main causes of human suffering and death went unnoticed at least based on public health outcomes. Enter the shiny new glamorous pandemic, SARS-CoV-2.

Even in the face of the current SARS-2 second version pandemic with massive numbers of "public mandates" still failing to resolve the outbreak of infection, global deaths are predominantly caused by NCDs such as obesity and its comorbidities. Seventeen years since The Lancet dressed down Public Health Institutions and little has changed toward reversing the NCD epidemic. Furthermore, the risk of comorbid diseases connected to what are often childhood onset NCDs (e.g., asthma, obesity) presents a staggering health challenge across the life course. For example, a diagnosis of childhood or adult asthma carries with it an elevated risk for at least 36 additional NCDs. For obesity, the prospects of a life-course filled with increasing disease are even worse. There are 43 recognized comorbid NCDs linked with obesity despite recent medical and public health efforts [9]. A recent National Health and Nutrition Examination Survey (NHANES) study reported that among seniors in the U.S., the rate of two or more NCDs is a staggering 91.8\% [10]. This can only be regarded as a public health failure. We have been staying the course in public health for too long and produced multimorbidity and reduced quality of life as public health outcomes.

\section{The Blame Game}

In general, public health organizations such as the WHO, CDC, FDA, NIH, EPA have placed the reason for the NCD epidemic squarely on the poor behavior of the public. If only the public would change their behaviors, the leading cause of global death would disappear. Presumably, we would return to the circumstances where death certificates read "died of natural causes," and old age would be a blessing rather than being a NCDridden, drug-addled existence. But a look at the very behaviors that organizations like the WHO say will solve the problem are less and less under the control of the individual. In fact, in this opinion article, I will argue that those behaviors are greatly impacted by the 
human microbiome, and the already-depleted human microbiome is under virtual assault from the actions of the very organizations that should be ensuring its safety. When government-mandated and/or -approved practices are inherently unsafe for the human microbiome, the "fault" in not changing microbiome-determined behaviors is no longer on the individual.

\section{Change is Overdue}

At the heart of the public health problem is that public health organizations, academic and governmental bureaucracies have failed to recognize significant new science when it comes to public application. For example, most schools of public health have faculty lines and research centers committed to microbiome research. But these research initiatives seem to be completely disconnected from actual public health intervention programs. How does that happen? In fact, the same 2004 editorial in The Lancet [3] could be republished today changing only SARS to SARS-CoV-2 and provide the same reality check for those institutions that practice public health. Academic public health programs need to make their new staffing count with microbiome-delivered solutions. We cannot wait a half century or more for a Microbiome-First NCD epidemic solution to bubble up. According to the World Economic Forum-Harvard School of Health report on NCDs [11], we do not have the luxury of even another decade of an unrelenting NCD epidemic.

\section{The Updated Science - Application Gap: Ancient Personal Responsibility Solutions to Stop NCDs}

The epitome of this reality gap in public-health related research and public health policy and initiatives can be seen in a comparison of two current World Health Organization (WHO) public webpages. The WHO appropriately emphasizes that NCDs cause the vast majority of global deaths (71\%) [12]. The threat goes beyond that of NCDs killing more humans in every country with each increasing year. As the World Economic Forum and the Harvard School of Public Health pointed out, the world cannot avoid the economic burden of the NCD epidemic. The human and economic toll is unsustainable. With the WHO having a clear vision of the threat, one would assume that this global public health organization is currently mobilizing the latest science to address this most serious human health challenge. That assumption would be incorrect. The WHO currently recommends that "cures" for the half century long NCD epidemic can be found in reducing four risk factors that involve four human behaviors: "tobacco use, physical inactivity, unhealthy diet and the harmful use of alcohol" [13].

This is not a new discovery by public health institutions nor is it a new "public health" effort. In fact, virtually the same health proclamations used by the WHO originated from ancestral healers dating back millennia to the time of the "Four Humors." Simply put, this is not new science as is discussed in the following. Despite centuries if not millennia of similar WHO-like behavioral admonitions, the NCD epidemic emerged during the $20^{\text {th }}$ century and now in the $21^{\text {st }}$ century is unrelenting. For example, the British medical journal published a study linking alcohol consumption and risk of cancer in 1903 [14]. A publication appeared in The Hospital in 1901 describing tobacco use and cardiovascular disease [15]. The sometimes public admonitions about diets are centuries old as detailed by Foxcroft [16]. Finally, recognition of the connection between inactivity and disease including NCDs is not new. Physicians in the ancient Indus Valley, Greece and Rome actually wrote prescriptions for exercise [reviewed in 17]. What is newer is the increased understanding that NCDs and inactivity can be a vicious cycle. NCDs such as gout make health-promoting exercise even more difficult as was noted by Benjamin Franklin [18]. 
As can be seen in Table $1[3,4,9,10,13,19-53]$, the danger in recent public health failures is not simply that time and money was expended in unsuccessfully combatting the NCD epidemic. It is that some of the recommendations actually further erode both the microbiome and human health. Several initiatives were not even health neutral.

Table 1. Thirteen Examples Reflecting Outcome-Based Failures of Public Health and/or Major Public Health Initiatives that Produced Underwhelming Results

\footnotetext{
Public Health Initiatives, Challenges, and Responses

The World Health Organization recently tabulated that the vast majority of global deaths (71\%) are caused by NCDs. However, they offer no plans seemingly capable of eliminating NCDs as the major cause of death.
}

The Global Burden of Disease Study illustrates the ongoing NCD epidemic but fails to even mention the microbiome among 87 risk factors and 369 diseases considered across hundreds of countries. It concluded that people are living more years in poor health despite medical advancements.

The extent of the failure of public health initiatives to address the decades-long NCD epidemic was revealed via a recent

NHANES study survey. The study found that $91.8 \%$ of senior adults in the United States carry two or more NCDs.

The public health failure regarding the epidemic of multimorbid NCDs associated with aging was compounded when public health institutions failed to adequately protect the NCD-riddled, pro-inflammatory, and hyper-vulnerable geriatric population against the SARS-CoV-2-induced lethal cytokine storm.

Public health mandates during the SARS-Covid-2 pandemic that further eroded the human microbiome instead of protecting the microbiome and the microimmunosome.

The National Children's Study was a grand 2000 Congressionally mandated, NIH led inter-

\section{Reference(s)}

[13] 
federal agency plan to prioritize early life health risk identification and prevention as the keys to better health both for children and across the lifespan. It was closed in 2014 with little to show for the very expensive initiative.

The Swine Flu incident beginning at Ft. Dix, NJ in 1976 and the rushed national vaccination program for a pandemic that never showed up proved to cause more health damage than good.

Public Health protection programs have repeatedly experienced "regulatory gaps" that permitted millions of people across multiple generations to be exposed to NCD-promoting toxicants before the hazard was eventually recognized. These safety testing gaps are not tied to a lack of microbiome safety evaluation. Examples of such global exposures to "safe" chemicals include: asbestos, trichloroethelene, dioxin, polychlorinated biphenyls, plasticizers including bisphenol A, atrazine, triclosan, perfluorinated compounds, microplastics, certain nanoparticles, and other endocrine disruptors and obesogens.

A plethora of food, food additives, drugs, and environmental chemicals previously- approved by the FDA, the USDA, and the EPA have been shown to significantly damage the microimmunosome posing a significant risk to human health. Screening for microimmunsome safety would have been useful as would regulatory action based on identified toxicity for the microbiome.

Medical Journal calls to reverse the Public Health failure of the NCD epidemic has produced little effect. 


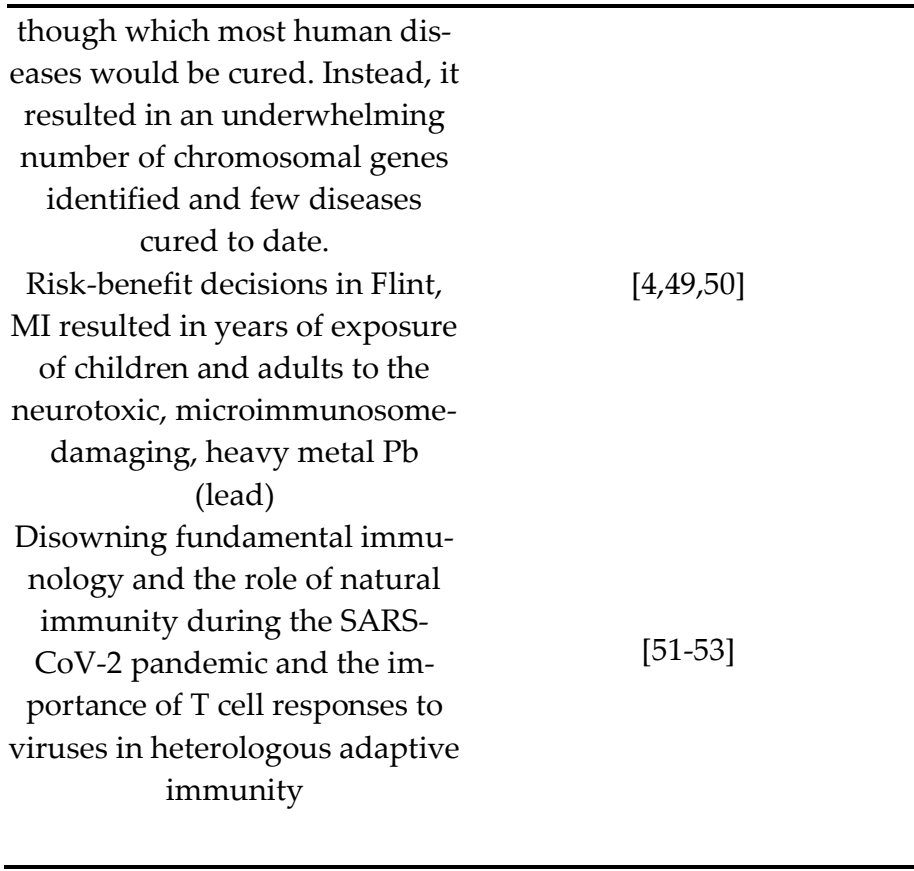

\section{The Global Burden of Disease Study}

In addition to the ancient dogmas perpetuated by the WHO, other promising initiatives have also ignored human microbiome status as a risk factor for NCDs. One example is the massive and ongoing Global Burden of Disease Study centered in Australia. The study includes analyses of 87 risk factors across more than 200 countries [19]. However, none of these risk factors directly pertain to the microbiome. The closest relevant indicator involves breast feeding practices. Many of the risk factors are direct outcomes of microbial dysbiosis (e.g., metabolic profiles) but the majority causative gene pool (microbial) determining relevant metabolic status is not considered. It is worth asking how long this study must go on before the microbiome and NCDs are included. It can be argued that to date, this massive study has been working on the margins of core risk factors for the human superorganism. The factors tracked across more than 200 countries fall more into the category of general umbrella behaviors as well as downstream "effects" of microimmunosome dysbiosis/misregulation rather than core causes of NCDs. The only exception in the study might be the inclusion of breastfeeding behaviors. More human systems biology-relevant parameters based on research of the past decade would be useful. These would focus on direct causes of: 1) improperly seeded, fed and/or damaged human microbiomes, 2) loss of barrier function, 3) pathobiont predominance, 4) changes in bile acid and other metabolism, microbial production of short chain fatty acids and regulatory peptides, and 5) induction of immune inflammatory dysregulation [9]. 


\section{NHANES Results Illustrate That Multimorbid NCDs with Polypharmacy are the New Norms}

As was discussed by Dietert [9], a recent NHANES study provided a stunning indicator of the failure to address NCDs among the U.S. aging population [10]. The NHANES surveys are not a new public health initiative. Instead, they are a regularly occurring, comprehensive, and comparative group of indicators that illustrate public health progress or failure among a large sampling of the U.S. population.

\section{Failure to Protect Multimorbid NCD-Bearing, Pro-inflammatory Seniors Against the SARS-Covid-2-Induced Cytokine Storm}

As discussed in Dietert [21], SARS-CoV-2 showed us the extent to which the ongoing NCD epidemic had not been adequately addressed via preventative and therapeutic medicine. Importantly, it is the additional lack of success in public health that allowed the NCD epidemic to progress. With decades of public health initiatives having failed to halt the multimorbid march of NCDs with aging, it was a double tragedy that the most vulnerable population for death by SARS-CoV-2 (those with multimorbid NDC burdens, a damaged microimmunosome and with misregulated inflammation) were not adequately protected. Because cytokine storms represent a misregulated inflammation response in tissues and because of the proven risk of the geriatric cohort to secondary bacterial pneumonia, the selective targeting of the segment of the population by Covid-19 was easily predictable. Yet, despite our clear understanding of NCD-related immune dysregulation, the public health response was poor $[54,55]$.

\section{The National Children's Study}

The National Children's Study (NCS) was a significant inter-federal agency early life health effort to address the increased environmental vulnerability of children for risk of disease and the nature of developmental programming for both infections and NCDs [26]. It was created by the Children's Health Act of 2000 and would eventually enroll H.R.4365 - 106th Congress (1999-2000). As described by the NIH Children's Health Study Archive site (https://www.nichd.nih.gov/research/supported/NCS), the Pilot study began in 2009 and enrolled 5,000 children across 40 U.S. locations. The primary study was designed to have followed 100,000 children. It involved a pregnancy to adulthood study with exposure-outcome indicators. Because of the ideas surrounding critical windows of developmental vulnerability [56], developmental origins of health and disease (DOHaD) [57], and powerful research findings on transgenerational epigenetic programming [58], the NCS held great promise. The original Congressional Act specified such NCDs as autism, juvenile diabetes and other NCDs. After only five years into the program, the NIH Director closed the NCS in 2014. What had begun as the promise of providing key information into the early life programming of NCDs became little more than a very expensive, truncated trial. The death of the NCS led to what has been termed scientific humiliation at a cost of 1.3 billion dollars when then and present Director of the NIH, Francis Collins, killed the program [28].

Public Health done correctly with the NCS would have produced highly useful results for protecting prenatal, infant, and childhood periods of vulnerability. Additionally, had the microbiome been included in the plan, the fact that microbiota determine individual risks to food, drugs, and environmental toxicants would have been revealed and might have led to better preventative medicine against NCDs sooner rather than later [9,59-62]. 


\section{Public Health Failures Among Regulatory Agencies}

Two categories of public health regulatory failures are listed in Table 1 . The first concerns major misses or "regulatory gaps" in safety evaluation resulting in millions of people across more than one generation being exposed en masse to toxic drugs, chemicals, or food additives. These exposures were later shown to contribute to both system(s) dysfunction and one or more NCDs. The first category illustrates general toxicity misses not necessarily linked to the microbiome. The second category concerns the lack of relevant safety testing specifically involving the microbiome.

Dietert and Dietert [63] discussed the problem with public trust for FDA and USDA stamps of approval when it comes to safety including that for the human microbiomes. But the issue of effective public health protection by regulatory agencies goes beyond just the tendency to embrace outdated science and cling to status quo (decades old) safety evaluation strategies. The problem is that once the errors in safety testing and human health protection are revealed, massive NCD-promoting exposures have already occurred and offending toxicants may or may not be removed from use by the responsible public health agencies. For example, food emulsifiers are clearly obesogens via their capacity to destroy the keystone gut bacteria, Akkermansia mucinophila, compromise the gut barrier, allow pathobionts to gain predominance, and produce underlying immune-inflammatory dysregulation $[64,65]$. Yet, the FDA has not acted to protect consumers from this pervasive food additive hazard despite the fact that reducing the prevalence of obesity is among the highest public health priorities $[66,67]$. When the WHO directs people to eat healthier foods to reduce obesity, are they considering elimination of most emulsifier-containing foods or at least replacing emulsifiers with a microbiome friendly alternative?

The public health problems extend beyond food additives to environmental chemicals that can also reach us via the food chain. As a result in the U.S., the EPA, the National Toxicology Program (NTP) and the FDA were all involved in the safety evaluation surrounding major plasticizers such as bisphenol A (BPA). Despite BPA being an endocrine disruptor, a widespread chemical, and having a variety of toxicology red flags that show up over the years, the politics of BPA made elimination of exposure challenging [68]. While BPA has adverse effects on many different tissues and organs (particularly NCDs involving the reproductive system), recent studies suggest that it is an obesogen $[69,70]$. Pérez-Bermejo et al. [71] recently reviewed the role of BPA in obesity and diabetes and concluded that it can stimulate adipocyte hypertrophy and disrupt glucose metabolism and insulin homoeostasis. Exposures in early life present the greatest risk of BPA promoted obesity. The researchers concluded that endocrine disruptors like BPA likely contributed to the increased prevalence of obesity. They also note that while some countries have taken steps to limit exposure of their population to BPA, there is still a lack of international agreement that would globally ban BPA. Finally, BPA has been reported to play a pathogenic role in Crohn's Disease working though the microimmunosome to increase bacterial translocation and increase systemic inflammation [72].

If the WHO wants to reduce NCDs including obesity, getting rid of obesogenic emulsifiers and endocrine disrupting plasticizers would be a great place to start. It is not the public's fault when good choices in diet, exercise, attempts to reduce tobacco and alcohol use are undermined by massive multigenerational hidden exposures to hidden products that damage the microimmunosome and promote obesity as well as other NCDs. Modifying personal behavior to reduce the risks of NCDs is only useful if microimmunosome damaging drugs, chemicals, and food additives are not embedded within every household food as part of everyday life. Microbiome First oriented physicians, nutritionists and other health practitioners could restore the human microbiome, but inadequate public health actions would erode it yet again on a daily basis. 


\section{The Final Group of Problematic Public Health-Related Activities}

The 2004 medical journal alarm on Public Health (Table 1) and the lack of effectiveness when it comes to NCDs was previously discussed at the beginning of this article. The Lancet article was not a new public health project. Rather, it provided an important timestamp for the ongoing effort of public health institutions to bring the NCD epidemic to an end. The problem is that today's approach by institutions like the WHO seems to be largely the same 17 years after being called out by The Lancet. It seems clear that a sea change is in order rather than annual tweaking of the same approaches that got us into a healthcare-threatening epidemic.

One of the great public health promises at the end of the $20^{\text {th }}$ century and the beginning of this century was The Human Genome Project [73,74]. Mapping and analysis of the complete human genome was touted as providing the wherewithal to cure most if not all NCDs. The project did map the human genome, but the results were underwhelming both in terms of number of chromosomal genes and the impact of that information on human health [75]. The silver lining in this failure was that it paved the way for The $\mathrm{Hu}$ man Microbiome Project and the 100-fold-plus number of human microbial vs. chromosomal genes that would be tallied. It should be clear now that the promised cures for NCDs reside minimally among our chromosomes and to a much greater extent belong to our microbial co-partners.

In 1976 a rare diagnosis of swine flu on the Ft. Dix military base in NJ led to what in hindsight was an overreach and overreaction of U.S. national public health. The feared pandemic never emerged, but a rushed vaccine that was administered nationally by the government did. The risk-benefit was poor with Guillain-Barre Syndrome among the adverse outcomes [29,30].

As shown in Table 1, a local public health-related initiative in Flint, MI led to a change in water supplies producing an almost unthinkable outcome [76]. It also showed that the breakdown of deliverable public health was not simply at one level of administration.

Ironically, during the later 1990s-early 2000s, federal agency grant programs, like the external funding program of the EPA, went through a period where research proposals to examine toxicity of environmental chemicals specifically excluded the heavy metal lead. Proposals on any other environmental chemicals were allowed. Because the author had been researching lead over this period, these exclusions brought the lab's lead immunotoxicity research to an end. The logic was that we knew everything we needed to know about lead or at least enough to know that we must avoid the exposure of children to lead at all costs. Yet, decades later in Flint, MI, public health protection failed us as has been noted by some of the most prominent environmental health researchers $[4,50]$.

The examples of public health failures listed in Table 1 show that rather than solving the most lethal health crises of the past half century (NCDs), an assault on the human superorganism has been permitted to continue where large-scale public exposures are permitted to occur before the actual, relevant risk-benefit is known and made public.

Mass exposures to bisphenol A should not have happened and daily exposure to glyphosate, food emulsifiers, and microbiome-damaging drugs should not be occurring. Dedication to the protection and nurturing of the human microbiome is probably the single most effective tool that public health initiatives could embrace to end the epidemic of lethal human diseases, the painful suffering of populations with multimorbid NCDs, and the reduced quality of life over much of the life course. 
Finally, the SARS-CoV-2 pandemic and the public health push for global mass vaccinations led to a remarkable seeming amnesia on a fundamental basis of immunology: the development of natural immunity and protection of the host via heterologous adaptive immune responses. The responses are tailored to the protection against the pathogen since they engage the millennia-honed combination of innate and adaptive immune processes that were effective against the category of pathogens across centuries and are characterized by both specificity and memory. When public health challenges arise, it is definitely not the time to forget fundamental natural disease resistance processes established over decades and funded by the very same institutions responding to current health crises. This would be a prescription for continuing the records of poor public health initiative outcomes reflected in Table 1.

\section{Transforming Public Health for Impactful Successes Against the NCD Epidemic}

This review provides three inter-related categories of microbiome-based defense against the ongoing NCD epidemic that have the ability to transform the recent string of public health failures/tragedies into meaningful progress in the fight against the NCD epidemic. This is not intended to be an exhaustive list of microbiome-based approaches to combat NCDs, but are simply examples illustrating how public health can and should change its focus to be compatible with the biological reality of humans (i.e., as superorganisms/holobionts.)

\subsection{Barrier Integrity, Regulation, and Protection}

The first category focuses on the integrity of the microimmunosome and, in particular, barrier function (e.g., skin, gut, airways, urogenital tract). There is an emerging concept that barrier protection should be a prime directive in the battle against NCDs such as the allergic triad [77]. Consider when and where compromising barrier integrity is a healthful change, and the problems can be put in perspective. It is never a good thing when bacteria and/or bacterial toxins translocate to part of the body where those bacteria do not belong. That is one of the fastest routes to disease and sometimes sepsis.

Starting with the skin, the largest organ in the body, there are commensal microbes that both regulate the health of the skin barrier and provide colonization resistance against pathogenic bacteria and viruses. Skin commensals influence cutaneous immune cells affecting the balance of immune inflammation and wound repair as well as innate immunity against vaccine viruses [78]. Clearly, skin commensals offer a manageable and useful strategy to ensure natural protection against pathogens entering via the skin as well as improper immune inflammatory responses. Recent studies on skin microbes suggest that strains matter. It is the actual collections of genes with Staphycoccus epidermidis (Staph $E$ ) that determine the extent to which it afford potent antimicrobial protection. A recent study suggested that transplantation of Staph E and Staphylococcus hominis works in animals, and that peptides from these commensals kill Staphylococcus aureus (Staph A) [79]. Finally, a recent meta-analysis suggests that probiotics can be effective in preventing childhood atopic dermatitis providing a new avenue for reducing the risk of NCDs [80]. In double blind, placebo-controlled studies, certain probiotic strains were found to be beneficial in the treatment of childhood atopic dermatitis [81]. A full range of skin transplantation competitive exclusion strategies was recently reviewed by Callewaert et al. [82].

In mucosal tissues where the barrier is protected against pathobionts by active regulation of the mucin layers, there are key microbial biomarkers that affect both barrier status and risk of specific NCDs (e.g., obesity/metabolic syndrome). In the gut Akkermansia mucinophila is known as a Keystone species because of its critical role in mucin regulation and protection of the gut barrier. It is one of a small number of bacteria that 
can perform this critical function. Risk of obesity and metabolic syndrome in general is inversely correlated with the levels of this bacterium [83]. As a result, this bacterium has been labeled as the "sentinel of the gut." [84]. Recently identified pilli-like outer layer proteins on the bacterium are important in both immune regulation and effective barrier function [85].

Any public health organization worried about the prevalence of obesity and metabolic syndrome related NCDs, should be worried about measuring and monitoring Akkermansia mucinophila. Eating healthier diets will mean little if other factors are destroying a person's gut barrier protecting bacteria. There are specific dietary factors that serve as prebiotics for Akkermansia [86]. But if the WHO is not focused on educating the public about the microimmunosome (the microbiome, a healthy barrier, and the underlying immune system) and specific prebiotics to aid the gut lining, then simply pushing the public toward what is perceived as "a healthier diet" may not have the intended effect.

In fact, it appears that Akkermansia mucinophila can also be useful as a probiotic for improving the safety of drugs with harmful side effects in the gut. One case is for the antipsychotic drug, olanzapine, which causes disrupted glucose homeostasis. In lab animal studies, probiotic Akkermansia mucinophila strains eliminated this metabolic syndrome inducing side effect [87].

In the airways, epithelial barrier status is critical in the risk of a wide array of airway diseases [88]. Additionally, early microbiota-immune interactions in the airways determine the course of airway mucosal immunity and risk of airway disease [89]. One of the considerations for the airway microimmunosome is whether the pathobiont Staph $A$ is carried in the infant nasal passages. As recently reviewed by Coleman et al. [90], the carriage of Staph A presents an increased risk for asthma (and other allergic conditions). This gram positive pathobiont has toxins and enzymes that can serve as allergens and sensitizing agents for the mucosal immune system [91]. Additionally, it can stimulate Th2 inflammatory cytokine production by epithelial cells that can result in barrier damage. The infant epithelial lining is particularly susceptible to pathobiont-associated damage because there is decreased production of epithelial-derived antimicrobials in early life [92]. Because antibiotics can often lead to only a short-term benefit with longer term complications as a probable outcome, effective colonization resistance against Staph $A$ in the infant airways is the best benefit-risk strategy [93,94]. As was discussed for the skin, Staph $E$ is a key bacterium in nasal maturation and natural defenses against pathobionts like Staph A [95]. But this can only happen when ecologically managing microbes is a medical and public health priority.

\section{The WHO and Its Four Modifiable Behaviors to Defeat NCDs}

In attempting to halt the ongoing NCD epidemic and eradicate NCDs, the WHO has focused on four modifiable behaviors. Rather than a true public health strategy based on recognition of the human holobiont and microbiome-exerted control over much of human behavior, the WHO has defaulted to a single-species educational program designed to admonish the publish on their own shortcomings. Essentially, WHO's solution to NCDs is that if only the public changed what they do, NCDs would go away. But as this review will show, the very behaviors the WHO believes are readily changed in each individual are in many cases only changed if and when the dysbiotic microbiome is rebiosed.

Public Health programs will never return to their early, glory day successes until and unless they embrace and apply Microbiome First approaches and proactively help people to usefully manage their co-partner microbes. NCDs are not the fault of the public when the most common food, drug and environmental chemical exposures damage the human 
microbiome. Rather NCDs are more the fault of woeful public health regulatory activity that fails to protect the human (and other) microbiomes.

The following sections illustrate how the microbiota impact and control the WHO's NCDrelevant human behaviors. Because the WHO indicate that the four most significant risk factors for NCDs involve personal behavior, the WHO's direction for individuals to change these behaviors (in the absence of holistic public health support for these changes) is a form of mandate with similarities to what has been seen during the SARS-CoV-2 pandemic.

\section{WHO Behavioral Modification \#1: Eat a Healthy Diet - (In Spite of the Microbiota- Driven Sense-Diet Cycle)}

We experience life much through our senses. But what is becoming clear is that sense-driven life experiences are significantly affected by our microbiome. If you want to get more out of life and have richer experiences, rebalancing the microbiome is the first place to start. We can go back to the WHO's approach to solving the NCDs epidemic in general and the obesity epidemic specifically by admonishing people for eating a poor diet and telling them to eat healthier. The public messaging belies a lack of practical consideration on how one overcomes microbial control of the body's taste sensitivities, food choices, and eating behaviors to facilitate a holistically-compatible shift in diet.

We now know that our partner microbes have a myriad of ways to affect virtually every aspect of our diet, food consumption, food preferences, and nutrient extraction from the foods we do eat. One of the key starting points for our relationship with food is taste (as well as smell). Our oral and gastrointestinal microbiota are essentially the miners of the nutrients we receive from our food. What we get from food depends upon what we eat but also on what the microbes do as per extraction and metabolism of the food. Table 2 [96-112] illustrates examples of research into the relationship between taste, food choices, and eating. Other factors such as smell/odor detection, satiety, and addictions follow in subsequent tables. Importantly, the following tables also demonstrates the key role of our microbiota in determining both threshold levels for taste and smell behavioral reactions to those cues. It affects not just our food preferences and eating behavior, but also our appetite and satiation. In the end microbiome dysbiosis plays a central role in eating disorders and can drive unhealthy eating both consciously and unconsciously. The take home message across the studies is that in order for the WHO's instruction to eat healthier to produce a truly successful outcome, the individual's microbiota need to be congruent with the taste, smell and energy sources associated with a healthy diet. 
Table 2. Microbiota and the Regulation of Taste

\begin{tabular}{|c|c|c|c|c|}
\hline Sense & $\begin{array}{l}\text { Test Species/ } \\
\text { Group }\end{array}$ & $\begin{array}{l}\text { Microbe(s) In- } \\
\text { volved/Subjects } \\
\text { Discussed }\end{array}$ & Effects & Reference(s) \\
\hline Taste & $\begin{array}{l}\text { Human } \\
\text { (with some mouse } \\
\text { research brought in) }\end{array}$ & $\begin{array}{l}\text { Staphylococci, Strepto- } \\
\text { cocci Actinomyces, } \\
\text { Lactobacillus Prevotella, } \\
\text { Porphyromonas } \\
\text { Actinobacteria and } \\
\text { Bacteroidetes Actinomy- } \\
\text { ces, Oribacterium, } \\
\text { Solobacterium, } \\
\text { Catonella, } \\
\text { Campylobacter Clostridia } \\
\text { Proteobacteria, Prevotella } \\
\text { Streptococci mutans }\end{array}$ & $\begin{array}{l}\text { In this review article, } \\
\text { these bacteria have been asso- } \\
\text { ciated with changes in spe- } \\
\text { cific aspects of taste. }\end{array}$ & [96] \\
\hline Taste & $\begin{array}{l}\text { Human } \\
\text { (emphasis on } \\
\text { dental patients) }\end{array}$ & $\begin{array}{l}\text { General review of } \\
\text { broad scope on taste } \\
\text { and including smell. } \\
\text { The impact of } \\
\text { biofilms is } \\
\text { considered. }\end{array}$ & $\begin{array}{l}\text { This review emphasizes the } \\
\text { life course ramification of fla- } \\
\text { vor biases and the potential } \\
\text { risk to the aging population. }\end{array}$ & [97] \\
\hline $\begin{array}{l}\text { Taste } \\
\text { thresholds }\end{array}$ & $\begin{array}{l}\text { Human } \\
\text { (preschool } \\
\text { children) }\end{array}$ & $\begin{array}{l}\text { Oral microbiota } \\
\text { affecting sweet } \\
\text { taste thresholds } \\
\text { in children }\end{array}$ & $\begin{array}{l}\text { This is an important } \\
\text { study showing that } \\
\text { preschool with a lower } \\
\text { threshold for perceiving } \\
\text { sugar consumed less sugar, } \\
\text { had fewer dental caries, and a } \\
\text { general lack of oral Streptococ- } \\
\text { cus mutans. The reverse was } \\
\text { true for children with high } \\
\text { thresholds for perceiving } \\
\text { sugar. }\end{array}$ & - \\
\hline Taste & $\begin{array}{l}\text { Human } \\
\text { (adults and youth) }\end{array}$ & $\begin{array}{l}\text { This was a } \\
\text { crowdsourced } \\
\text { population study of } \\
\text { adults and youth. } \\
\text { Treponema was } \\
\text { found in the oral } \\
\text { microbiome of }\end{array}$ & $\begin{array}{l}\text { The observation of Treponema } \\
\text { in youth suggest it might be a } \\
\text { biomarker for later oral } \\
\text { health problems and con- } \\
\text { nected in some way to the } \\
\text { childhood obesity. This study } \\
\text { did not find a microbial }\end{array}$ & [99] \\
\hline
\end{tabular}


Taste

Taste

Taste

Taste

Taste thresholds and intensity adults with dental

problems and

of obese youth.

Human

Human

(dental patients, teenagers and young adults)

Human

(men)

Human

(diabetic patients)

Examined type 2 dia-

betic patients for oral

microbiota signatures

within the circumval-

late papillae (CVP)

that relate to fatty

taste perception.

Analysis of

orosensory

perception of lipids

and sweets in sweetness taste difference

among the crowdsourced

sampling.

The tongue microbiome and

[100]

its dysbiosis can be a large

contributor to metabolic dis-

orders that facilitate obesity,

diabetes and cardiovascular

disease.

Specific oral microbiota were

[101]

associated with

sugar intake. However, there

were several distinct ecologi-

cal combinations of microbi-

ota that were associated with high sugar intake.

Decreased fatty taste perception was associated with elevated Bacteroides genus and Clostridium_XIV and decreased Lactobacillus compared against the high fatty taste perception group.

Impaired fatty acid

perception is not driven by insulin resistance but rather is affected by microbiota dysbiosis. Additionally, some drugs (e.g., metformin, statins) may affect lipid sensitivity perception

Low numbers of patients and [104] high individual variability produced few statistically

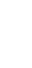




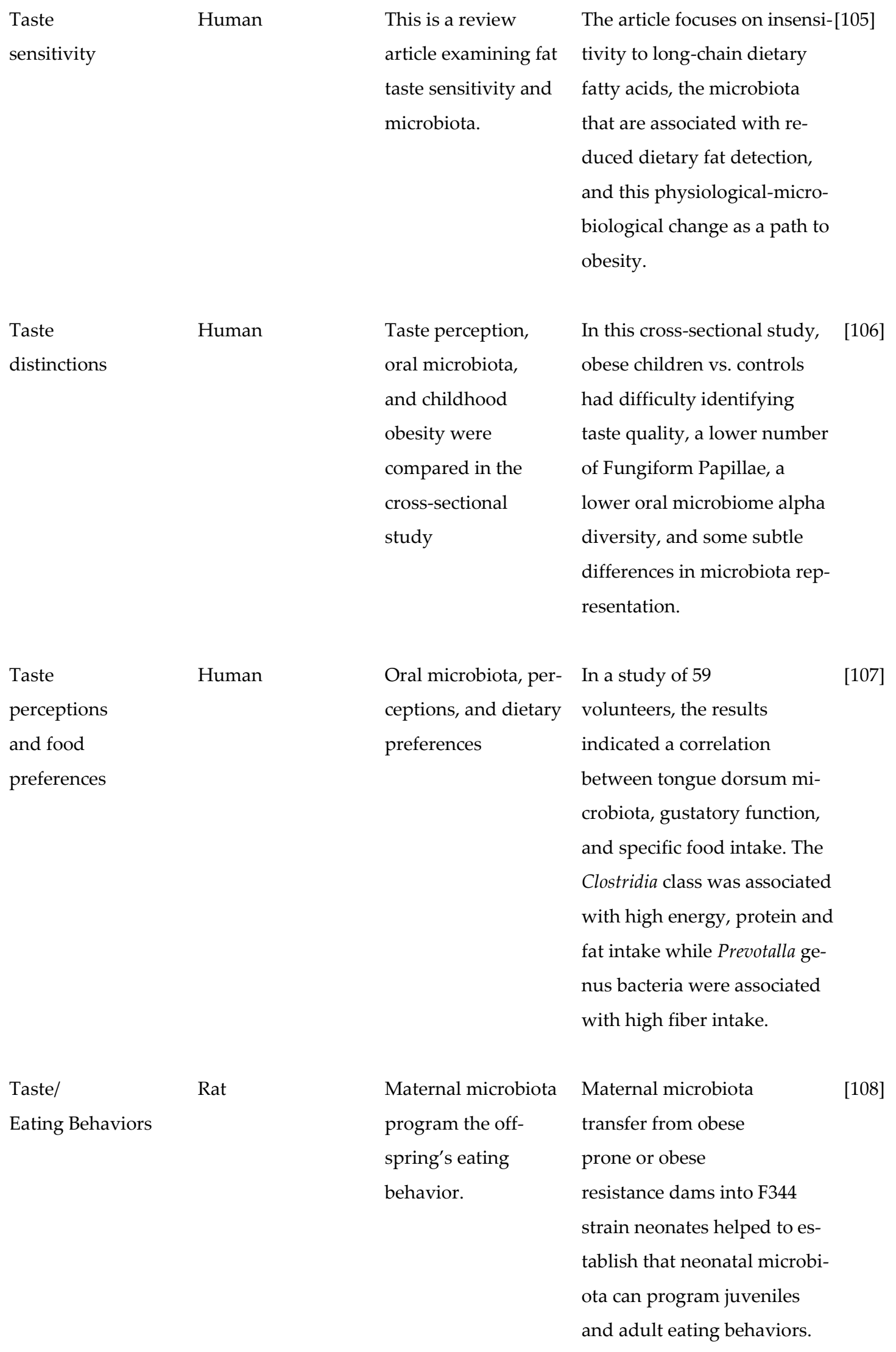

adult females follow- significant differences be-

ing different types of yond a

gastric surgery microbiome signature.

This is a review

The article focuses on insensi-[105]

taste sensitivity and

fatty acids, the microbiota

that are associated with re-

duced dietary fat detection

and this physiological-micro-

biological change as a path to

obesity.

Taste perception,

In this cross-sectional study,

106]

had difficulty identifying

of Fungiform Papillae,

diversity, and some subtle

Oral microbiot:

volunteers, the results

indicated a correlation

and specific food intake. The

Clostridia class was associated nus bacteria were associated

with high fiber intake. 
Mouse

Prebiotic modulates

sweet taste

Perception

Taste/

Drosophila

research model

behavior

study

Drosophila

research

model study

behavior

Taste and Smell
Ingestion of foreign

\section{perception in}

obese mice

microbiota produced

a strong shift in

dietary preferences.

tion of microbiota derived

from a different Drosophila

species.

Strong dietary prefer- Commensal bacteria were

ences controlled

by the metabolism

of commensal

bacteria.

Oral microbiota

metabolism affects

flavor perception

thresholds via

multiple routes. Taste

and smell perceptions

are both affected.
[111]

shown to direct food prefer-

ences via metabolic activity

and could overcome some di-

rect effects of the food itself.

Comprehensive coverage of

[112]

the multiple pathways

through which both taste and

smell are affected by microbi-

ota.
This programming did not

require the transferred micro-

biota to persist into adult-

hood. It is a microbiome-

based example of DOHaD.

An inulin-type fructan prebi-

[109]

A strong food aversion was

[109]

preference by repeated inges-

administered to diet-induced

obese mice for 12 weeks.

pro-

Bifidobacteria and Akkermansia

y

perception of sweet com-

pounds. 
43 comorbid NCDs across the lifespan. As a result of these comorbidities, the metabolic syndrome complex which includes obesity is one of the most insidious plagues on modern humans and a huge contributor to both premature death and reduced quality of life.

Not surprisingly, the public health solutions for the obesity epidemic must overcome two massive roadblocks: 1) rampant microbiome dysbiosis that locks in destructive eating behaviors and 2) the inexplicable presence of obesogens permeating both our environment and most of our food. Rather than simply telling people to eat a healthier diet and then being mystified by the poor outcomes among the NCD-at -risk and NCD-burdened populations, public health organizations should be showing people how to align their microbiome with eating a healthier diet. Secondly, public health organizations should get obesogens out of the environment and food chain. They should never have been there in the first place, and they certainly should not be there now. Microbiome rebiosis can only work if the almost constant exposure to obesogens is eliminated.

\subsection{Taste}

Do gut microbes taste? [96] See Table 2. That is addressed by Leung and Corvasa [96] in their recent review. There are five tastes that human can not only detect but also evaluate for quality: sweet, bitter, salty, sour, and savory. It is also possible we can distinguish fats (e.g., linoleic acid). The tongue is a perfect design for biofilm formation. Depending upon the thickness of a bacterial biofilm on the tongue, taste receptors can be blocked from engaging specific foods.

Gut microbiota control taste through three inter-related processes. First, they can directly interact with the barrier between food and taste receptors, screening and/or blocking access to your taste receptors. Blocking the taste receptors through biofilm formation can have consequences for food intake and eventually health. Secondly, our microbes can affect taste though hormone interactions.

Finally, microbiota affect taste via the immune system. Taste receptor bearing cells have to turn over and inflammatory processes resulting from loss of barrier function and/or colonization resistance can allow lipopolysaccharide (LPS) to activate innate immune cells increasing pro-inflammatory cytokine concentrations. As these spread, both taste cell receptor expression and taste thresholds change [96]. This is another reason why barrier integrity is crucial. Taste buds can have a delayed renewal and a shorter lifespan when microbiome-immune interactions go wrong. Of course, this is the steady state physiology when patients carry NCDs. Microbiome dysbiosis-induced inflammation essentially kills taste buds. The microimmunosome must be engaged first if you want people to readily shift to a healthier diet.

Several recent studies focused on very specific microbiota regions and also very specific taste biases. The importance of the oral microbiome for taste and flavor to dental health was recently described by Ellender and Moynihan [97] with an emphasis placed on the life course/aging impact of flavor biases.

Jurczak et al. [98] conducted an important study of preschool children (2-6 years of age) comparing sugar threshold perceptions, amount of sugar consumed, dental caries, and culture based oral cavity bacteria and yeast. The results showed that the presence of Streptococcus mutans was associated with a poor sugar detection profile (high threshold concentrations of sucrose were required before it could be perceived), higher sugar consumption, and higher prevalence of dental caries. This is one example of a key bacterial marker and sweet detection profile that drives specific food consumption and resulting oral pathology. 
A second study of oral health was a crowdsourced sampling population study conducted via the Denver Museum of Nature \& Science [99]. One interesting observation was that an oral pathobiont, Treponema, was detected most often in adults with dental problems and in obese youth. Li et al. [100] discuss the tongue microbiome, its effect on taste receptors and the routes through which tongue microbiota dysbiosis can directly and indirectly promote obesity, diabetes and cardiovascular disease.

Dysbiotic microbiota can drive taste bias that promotes a vicious cycle of eating foods that both maintain the specific dysbiosis and cause inflammatory-driven disease. Three studies illustrate these cycles for microbial control of sugar craving and fat craving. Esberg et al. [101] connect specific communities of oral microbiota with elevated prevalence of dental caries and high sugar food intake. Two studies from Besnard et al. [102,103] dealt with oral microbial regulation of fat taste sensitivity as relates to obesity and diabetes. In the first study by Besnard et al. [102], the microbial composition of the mouth's gustatory circumvallate papillae (CVPs) was analyzed and compared among obese adult men as it related to low vs. high sensitivity of fat taste perception. The decreased fatty taste perception in low-lipid tasters was associated with elevated levels of Bacteroides genus and Clostridium_XIV bacteria and a decreased level of Lactobacillus bacteria compared with the corresponding microbial composition in the high lipid taste perception group. Based on an analysis of metabolic pathways, the investigator hypothesized that prevalence of methanogenesis pathways may be directly, positively correlated with fatty taste sensitivity. Note that fatty taste levels were independent of adiposity itself. Hence, the two taste sensitivity groups are likely to represent two distinct subtypes of obese individuals. In their second parallel study, Besnard et al. [103] examined diabetic patients for microbiota signatures in their CVPs in relationship to their fatty taste perceptions. Microbiota have been shown to affect sugar-fat perception balances via sensitivity-resistance to glucagon-like peptide-1 (GLP-1). The two take-away findings were that insulin resistance itself does not appear to control fatty acid sensitivity perception. Instead, that is related to the microbiota. Additionally, taking some drugs (e.g., metformin and statins) was found to affect fatty acid sensitivity [103].

In an important proof of concept study in rats, Pocheron et al. [108] performed cecocolonic and cecal content microbiota transfer experiments between selectively bred obese-prone (OP)/obese-resistant (OR) Sprague-Dawley dams into 1 Fischer F344 recipient pups from birth to 15 days of age. F344 sham inoculated pups were also evaluated. The inoculums contained different microbiota compositions. The different donor microbiota that were transferred programmed F344 eating behaviors even into adulthood. This was regardless of the duration of persistence of donor microbiota profiles in the recipient gut. The author concluded that neonatal microbiota profiles could program adult eating behaviors. This would be consistent with the Developmental Origins of Health and Disease (DOHaD) evidence [113] while demonstrating that the microbes themselves can program neonates.

In the Bernard et al., 2019 study [109] from Table 2, diet-induced obese mice were given an inulin-type fructan prebiotic supplement for 12 weeks. The supplementation partially corrected diet induced profiles. Importantly, it shifted both the cecal microbiota profiles toward reduced loss of barrier integrity and inflammation while simultaneously improving orosensory perception of sweet taste and associated behavioral changes. This study emphasizes the utility of using both diet/prebiotics and microbiome rebiosis to naturally produce healthier shifts in eating behavior. The question is when will such holistically supportive, microbially-based solutions become core to public health organization initiatives (e.g., WHO)?

Research studies in Table 2 demonstrate that one of the most effective ways to change diet is to change the microbiota. Heys et al. [110] illustrated a proof-of-concept study that 
changing microbiota can change dietary preferences. If the dietary preferences easily sync with a healthier diet, then changing to a healthier diet will not be opposed by the body's physiology-regulating microbiota. A study by Leitão-Gonçalves et al. [111] also supported the role of gut microbiota in controlling feeding behavior. By shifting the gut's microbial composition such that it promotes a healthier feeding behavior, one is more likely to succeed with a desired dietary change. This superorganism-based, holistic strategy would facilitate the desire of the World Health Organization that people simply eat a healthier diet (even if it is counter to their dysbiotic microbiome). A gut-microbiota to vagus nerve to brain pathway that can bypass taste receptor status is discussed in the addiction-withdrawal section.

A final point is the effect of high fructose corn syrup specifically on the human microbiome. In a study by Beisner et al. [114], researchers found that different formulation of foods containing fructose resulted in different gut microbiome compositions and metabolism. High fructose corn syrup supplemented foods resulted in destruction of beneficial butyrate producing gut bacteria and problematic microbial metabolism of host lipids. In contrast, naturally occurring fructose as part of a fruit-based diet appeared to produce an opposite beneficial effect [114].

\subsection{Smell}

Smell is one of the senses that is important in the choices we make in life. Our entire engagement with objects we encounter can be driven by odor detection and both conscious decisions (e.g., moving away from a skunk encounter) as well as unconscious decisions such as selecting one food within a buffet line over another. It draws us to things or away from things based on how we perceive odors. This includes our food as shown in Table 3 [115-118].

Table 3. The Role of Microbiota in Smell

\section{Sense}

Smell
Test Species/

\section{Group}

Mouse (three groups)

\section{Microbe(s) Involved/Sub- Effects}

\section{jects Discussed}

Characterization of
microbiota among three dis-
tinct
groups of mice: $\mathrm{C} 3 \mathrm{H} / \mathrm{HeN}$,
Swiss,

and BALB/cByJ. Germ free mice $(\mathrm{C} 3 \mathrm{H} / \mathrm{HeN})$ were

installed with

microbiota from

each of the three groups per-

mitting

olfactory, electro-olfactogram

recordings (EOG) of the epi-

thelium and microbiota com-

parisons on the same mouse

genetic background.

\section{Reference(s)}

Among 11 odorants

examined, several

differentially activated the ol-

factory epithelium linked to

the microbiota profile. The

findings suggest the im-

portance of the

microbiota in the olfactory ep-

ithelium physiology (e.g.,

EOG). 
Smell

Smell

Smell
Mouse and Human (Re- Chemosensory links between This is an important view) microbiota, olfaction and review article emotion are described and the "odorome" concept covering the capacity of bacis introduced. An terial products example of bacterial products and, in turn, to elicit specific discussed is $\beta$-phenylethyla- emotions.

mine.

Human

Bacterial signatures from

Odor thresholds, among

Actinobacteria, identification and

Bacteroidia, Bacilli,

Clostridia and

Proteobacteria were

associated with

hyposmic (i.e., odor

detection)

discrimination

were all evaluated

and found to be

linked by microbiota composition. Specific groups of microbiota affected combinations of the three categories.

threshold, low

discrimination

and low identification perfor-

mance. Corynebacterium and

Faecalibacterium were often bi-

omarkers for reduced odor

discrimination and threshold.

Comamonadaceae and Entero-

bacteriaceae were linked with

reduce thresholds and identi-

fication. Porphyromonas and

unclassified Lachnospiraceae

were associated with poor

performance across all three

olfactory performance catego-

ries.

Mice and Zebrafish

Mechanistic study in two ani- Found evidence for mal models

$$
\begin{aligned}
& \text { nasal microbiota } \\
& \text { regulation of } \\
& \text { olfactory } \\
& \text { transcriptional } \\
& \text { factors }
\end{aligned}
$$

As with taste there are thresholds of odor detection and there is the nature of the scent itself. One of the interesting tests concerns the tropical fruit, durian. The odor is so 
repulsive for some that the fruit is inedible. Others savor the flavor so much that the odor is of little concern. The fruit itself has a high alcohol content and can become an obsession for the alcohol addicted.

Morquecho-Campos et al. [119] recently reviewed the relationship between food odor, congruent appetite and food preferences. In particular the authors point out that we live in an obesogenic environment. Food groups with similar chemistry and odors can lead to what is termed sensory specific appetite (SSA).

Nardon et al. [115] found evidence that microbiota can affect the first step in odor detection at the level of the olfactory epithelium. Studies in three different groups of mice examined the effects of microbiota on nasal epithelium and odor detection and preferences in three different groups of mice using physiological, biochemical, behavioral, and microbiological analyses. The investigators used eleven odorants in the evaluation. They found that olfactory preferences were dependent upon two factors: 1) the identity of the odorant and 2) the microbiota profile. Remarkably, microbiota appeared to be capable of differentially activating the olfactory epithelium. Both enzyme production from the epithelial transduction system and electroolfactogram (EOG) signals depended upon the specific microbiota profile.

Some evidence exists on the mechanisms through which microbiota can regulate olfactory epithelium gene expression. Using two different animal models (mice and zebra fish), Casadei et al. [118] found that nasal microbiota control transcription programs in the host though differential production and activity of specific transcriptional factors. RE1 silencing transcription factor (REST) is a zinc finger transcriptional factor that is regulated by microbiota. In turn, REST affects the gene expression of many neurological system genes by binding to promoter regions. This affects not only olfactory function but also differentiation within sensory organs.

In a human trial (Table 3), Koskinen et al. [117] found that specific groups of nasal microbiota affected different combinations of olfactory performance/capabilities. These investigators measured threshold detection levels, the capacity to discriminate among odors and the capacity to identify odors. They found significant associations for the presence of specific microbiota groups with odor performance.

\subsection{Satiety}

While microbiota play a critical role in regulating taste and smell particularly as it pertains to food and food components, the role of microbiota in satiety is a third point in the pyramid of controlling diet and diet-related health. Satiety describes the sense of being full and satisfied as per appetite. The opposite of satiety is intense hunger that can lead to binging on food. It is not just food quality but also food quantity that affects the risk of NCDs [120].

Appropriate regulation of satiety is one of the important factors that connects diet, eating behaviors (e.g., meal size), and health. Table 4 [121-128] includes eight examples of recent studies and reviews on microbiota and the regulation of satiety. 
Table 4. The Role of Microbiota in Satiety

\begin{tabular}{|c|c|c|c|c|}
\hline Sense & $\begin{array}{c}\text { Test Species/ } \\
\text { Group }\end{array}$ & $\begin{array}{l}\text { Microbe(s) Involved/Subjects } \\
\text { Discussed }\end{array}$ & Effects & Reference(s) \\
\hline Satiety & $\begin{array}{l}\text { Review of } \\
\text { multi-species } \\
\text { studies (primar- } \\
\text { ily rodent with } \\
\text { some human) }\end{array}$ & $\begin{array}{l}\text { This recent review article details } \\
\text { the variety of mechanisms } \\
\text { through which gut microbiota } \\
\text { control satiety }\end{array}$ & $\begin{array}{l}\text { Microbiota were } \\
\text { demonstrated to control } \\
\text { both central and periph- } \\
\text { eral food intake mecha- } \\
\text { nisms. }\end{array}$ & [121] \\
\hline Satiety & $\begin{array}{l}\text { Review of hu- } \\
\text { man and mouse } \\
\text { studies }\end{array}$ & $\begin{array}{l}\text { Review article covering probiotic } \\
\text { and prebiotic studies on eating } \\
\text { and satiety. It also discusses the } \\
\text { categories of microbial peptides, } \\
\text { hormones, and products as well } \\
\text { as metabolites that affect hunger, } \\
\text { eating, and satiety. Most of the } \\
\text { probiotic studies cited used Lacto- } \\
\text { bacillus and/or Bifidobacterium spe- } \\
\text { cies. }\end{array}$ & $\begin{array}{l}\text { This review describes } \\
\text { the control of multiple } \\
\text { regulatory factors affect- } \\
\text { ing satiety that are em- } \\
\text { bedded within the gut } \\
\text { microbiome. It also } \\
\text { summarizes numerous } \\
\text { clinical and research } \\
\text { studies on microbiota } \\
\text { and appetite control. }\end{array}$ & [122] \\
\hline Satiety & Review & $\begin{array}{l}\text { Review article covering microbi- } \\
\text { ota-gut-brain axis in satiety regu- } \\
\text { lation }\end{array}$ & $\begin{array}{l}\text { The article is focused on } \\
\text { how we move toward } \\
\text { Microbiota-Gut-Brain } \\
\text { axis on a chip in vitro } \\
\text { assessment. }\end{array}$ & [123] \\
\hline Satiety & Review & $\begin{array}{l}\text { Review article detailing the regu- } \\
\text { lation of gut peptides and partic- } \\
\text { ularly ghrelin via gut microbiota }\end{array}$ & $\begin{array}{l}\text { This review article pro- } \\
\text { vides satiety-related evi- } \\
\text { dence that gut microbi- } \\
\text { ota regulates ghrelin } \\
\text { levels via short chain } \\
\text { fatty acids, specific } \\
\text { amino acids, formyl } \\
\text { peptides, LPS, and } \\
\text { H2S and also affects } \\
\text { ghrelin receptor } \\
\text { signaling. }\end{array}$ & [124] \\
\hline Satiety & Obese adults & $\begin{array}{l}\text { Lactobacillus rhamnosus } \\
\text { CGMCC1.3724 (LPR) }\end{array}$ & $\begin{array}{l}\text { This was a 24-week du- } \\
\text { ration (two 12-week } \\
\text { phases) double-blind, } \\
\text { randomized, } \\
\text { placebo-controlled trial } \\
\text { examining control of }\end{array}$ & [125] \\
\hline
\end{tabular}




\begin{tabular}{|c|c|c|c|c|}
\hline & & & $\begin{array}{l}\text { appetite, weight loss, } \\
\text { and mood. Positive } \\
\text { significant effects on sa- } \\
\text { tiety were seen in both } \\
\text { men and woman with } \\
\text { the latter experiencing } \\
\text { the greater benefit. }\end{array}$ & \\
\hline Satiety & Obese women & $\begin{array}{l}\text { A multi-species probiotic mix or } \\
\text { placebo was used in combination } \\
\text { with a caloric restricted diet. The } \\
\text { probiotic mix contained: Lactoba- } \\
\text { cillus acidophilus, Bifidobacterium } \\
\text { bifidum, Bifidobacterium lactis, } \\
\text { Bifidobacterium longum, Lactobacil- } \\
\text { lus rhamnosus, Lactobacillus reuteri, } \\
\text { magnesium stearate, and malto- } \\
\text { dextrin }\end{array}$ & $\begin{array}{l}\text { This was a 12-week du- } \\
\text { ration, randomized, } \\
\text { double-blind, placebo- } \\
\text { controlled clinical trial } \\
\text { of obese women. Posi- } \\
\text { tive effects were seen in } \\
\text { the probiotic supple- } \\
\text { mented group for both } \\
\text { eating behavior as well } \\
\text { as anthropometric indi- } \\
\text { ces. }\end{array}$ & [126] \\
\hline Satiety & Mouse & Lactobacillus rhamnosus GG & $\begin{array}{l}\text { Aged Balb/c mice were } \\
\text { fed regular or high fat } \\
\text { diet and two different } \\
\text { doses of probiotic sup- } \\
\text { plementation were ex- } \\
\text { amined for effects on } \\
\text { obesity-related bi- } \\
\text { omarkers including lep- } \\
\text { tin resistance. High dose } \\
\text { probiotic reversed the } \\
\text { leptin-resistance associ- } \\
\text { ated with diet-induced } \\
\text { obesity. }\end{array}$ & [127] \\
\hline Satiety & Mouse & $\begin{array}{l}\text { A prebiotic soybean insoluble die- } \\
\text { tary fiber was administered dur- } \\
\text { ing a 24-week intervention in } \\
\text { high fat diet mice. The special- } \\
\text { ized fiber induced increases in } \\
\text { Lactobacillus and Lachnospi- } \\
\text { race_Nk4A136_group with de- } \\
\text { creases in Lachnospiraceae and Bac- } \\
\text { teroidesacidifaciens }\end{array}$ & $\begin{array}{l}\text { The outcomes of the } 24 \text { - } \\
\text { week prebiotics inter- } \\
\text { vention and microbi- } \\
\text { ome shift were changes } \\
\text { in short chain fatty acid } \\
\text { production and an ele- } \\
\text { vation in satiety hor- } \\
\text { mones. }\end{array}$ & [128] \\
\hline
\end{tabular}


In a recent review, Rautman and de la Serre [121] describe the multi-level influences of gut microbiota on a variety of mechanisms (e.g., both peripheral and central) determining satiety. Evidence suggests that the composition of gut bacteria affects gut-brain communication such as peptide signaling via the vagus nerve. Another level through which microbiota composition controls satiety is by the regulation of both peptide expression and peptide release by endocrine cells within the gastrointestinal system (i.e., termed enteroendocrine cells). Among the peptides affected by microbial regulation are: cholecystokinin, glucagon-like peptide-1 and peptide YY. Beyond appetite-regulating peptide production, microbiota can affect the other end of the regulatory pathway: vagal afferent sensitivity to gut-originating satiety signals [121]. By affecting gut barrier integrity and inflammation, gut microbiota composition affects not only vagal afferent signaling but also the structural integrity of the gut-brain axis (via reduction of VAN numbers and c-fiber withdrawal).

Central intake mechanisms are also affected by microbiota. As described by Rautmann and de la Serre [121], bacterial inflammatory-inducing products can alter not only sensitivity to CCK and leptin but also cause a neuroinflammation-induced loss of function in pivotal brain regions: the nucleus of the solitary tract (NTS) and the hypothalamus. For example, certain species of bacteria appear to interfere with leptin sensitivity in the hypothalmus [121]. Installation of as few as a single probiotic bacterial species (Lactobacillus rhamnosus GG) was found to restore leptin sensitivity in diet-induced obese mice [127]. A final central intake mechanism regulated by microbiota composition is the collection of reward pathways [121].

This is particularly relevant to hedonic perception. Microbiota control of the reward pathway will be discussed later in relation to the WHO's mandate-like public health directive that in order to stop NCDs the public should cease addiction behavior. It should be noted that food addiction behaviors are an important part of addiction cycles, are an impediment to the WHO's instruction to eat a healthier diet and are significantly affected by microbiome status. Yet remarkably, the WHO's solutions to the NCD epidemic fail to constructively address this relationship, to inform the public of this relationship, and to provide the public with strategies for breaking the cycle of microbiome-regulated food addiction.

On satiety, Table 4 provides additional information on the regulation of satiety by specific gut microbiota. Three very recent reviews are included [122-124]. Two of the studies focused on adult obese humans while two studies were mouse preclinical studies that investigated microbiota associated with satiety hormone induction.

\section{WHO Behavior Modifications \#2 and \#3: Consume Less Alcohol and Stop Using Tobacco - (In Spite of the Microbiome's Role in Addiction and Withdrawal)}

The WHO indicated that priority NCDs risk reduction requires both the consumption of less alcohol and cessation of tobacco use. As with the other mandates from the $\mathrm{WHO}$, these are not new health promoting suggestions. The problem is that they are behavioral modifications that are particularly challenging for individuals to accomplish. The reason is that tens of millions of individuals suffer with substance use disorder (SUD). Such problematic changes are based in part on the addiction related aspects of food, alcohol, and tobacco use.

The problem is that these WHO behavioral modifications are presented as if it is as simple as deciding which fruit to pick up at a grocery store and ensure that the day's shopping does not include alcohol or tobacco products. But the instruction to make what seem like simple changes ignores: 1) SUD, 2) the highly addictive nature of these behaviors for many individuals, and 3 ) the long recognized potential addiction-withdrawal challenges connected to following these recommendations. 
Recent research has shown that the microbiome plays a major role specifically in SUD [129] and in our superorganism body's reward systems in general. In fact, the gut microbiome uses metabolomic, immune, neurological, and epigenetic mechanisms to control the presence of SUD. If the microbiome is dysbiotic as occurs with microbiota-damaging environmental, pharmaceutical and /or life course experiences, it may be difficult to nearly impossible to discard food or drug dependencies. Additionally, attempted withdrawal from addiction can be painful and as has been previously reviewed [130], pain is highly controlled by microbiome status. Hence, there are two very good reasons to be "managing microbes" first and foremost. The microbiome can help to minimize the risk of addiction and/or it can help to increase the likelihood of successful, minimally traumatizing withdrawal. In fact if one wants to modify any addiction, starting with the microbiome is great place to shift the reward-addiction chemical cycle.

In their recent review, Russell et al. [129] discussed the host genetic factors that are involved in SUD and then further detailed how gut microbiome status can either lock in the disorder or facilitate withdrawal and the likelihood of successful future abstinence. Among the substances reviewed under SUD are: alcohol, cocaine, opioids, nicotine and cannabis. Similarly, Forouzan et al. [131] reviewed studies concluding that gut-brain axis regulation by microbiota regulate psychostimulant abuse disorders and control the negative affects so important in the potential for relapse. In a similar vein, O'Sullivan and Schwaber [132] concluded that gut microbiota influence visceral-emotional hubs and the anti-reward pathway that is common in alcohol and opioid withdrawal avoidance.

The Russell et al. [129] review article also integrated the information from two prior rodent studies looking at the transplantability of alcohol depressive withdrawal symptoms. In the lab animal study, Xiao et al. [133] performed fecal microbiota transplantation from two-week alcohol-exposed mice into healthy recipients. Donor bacteria took up residence in the recipients, and these animals displayed both depressive behavior and rapid alcohol withdrawal anxiety upon exposure to alcohol. Zhao et al. [134] extended this work by transplanting fecal gut microbiota from alcoholic patients into antibiotictreated C57BL/6J mice. There was colonization by the transplanted microbiota and the recipient mice exhibited symptoms of alcohol dependency. These results suggest that the gut microbiome can carry sufficient metabologenomic information to produce alcohol dependency. Furthermore, other researchers have suggested that psychobiotics (probiotic bacteria affecting brain function and neurochemical balance) could represent a useful therapeutic strategy for alcohol use disorder [135].

The microbiome can impact virtually any addiction where the microbiota can: 1) metabolize the addictive food, drug or chemical, or 2) affect the brain chemistry connected to the behavior. Lucern et al. [136] recently examined the contributions of the gut microbiome-peripheral immune-central nervous system interactions in determining precisely who is likely to develop SUD.

The concept that the microbiota-drug interaction helps to lock in addiction is supported by Freedman et al. [137]. They found that patients receiving opioids in combination with antibiotics were less likely to become drug addicted upon hospital discharge. Presumably, the antibiotics disrupt the opportunity for a SUD profile to develop in the gut microbiome. Of course, rebiosis of the microbiome after antibiotic treatment is needed for two reasons: 1) to avoid loss to colonization resistance and potential elevated risk of NCDs and 2) to buffer against future SUD.

Evidence suggests that dysbiotic gut microbiota may carry the predisposition for alcohol abuse. Esquer et al. [138] bred generations of alcohol abusing rats and found that antibiotic treatment of rat pups prior to alcohol availability could significantly break the cycle of alcohol abuse. This was further enhanced by the oral administration of a probiotic, 
Lactobacillus rhamnosus GG. The investigators attributed the microbiota-controlled changes to reductions in both an alcohol-related pro-inflammatory state and sweet taste perceptions with the vagus nerve being key in communication to the brain.

For humans, Carbia et al. [139] presented an integrative model for alcohol misuse including the gut microbiome-immune system-brain axis. They cited a consistency across species in which Clostridiales, Ruminococcaceae and Lachnospiraceae are elevated in association with addictive behavior. Within their model, the microbiota in conjunction with dysbiosis-promoted inflammation are key elements of alcohol misuse and addiction. The adolescent period was identified as a window of particular vulnerability for this behavioral programming. In a related paper, García-Cabrerizo et al. [140] argued that because gut microbiota are critical in control of the SUD-associated reward system for drugs like alcohol, psychostimulants, opioids, and cannabinoids, they should be therapeutic targets for reversing SUD. The pathways leading from the gut microbiota to the brain can travel through the vagus nerve, the immune system, the HPA axis, bacterial metabolites and enteroendocrine cells [140].

Evidence suggests that rebiosis of a dysbiotic gut microbiome can reduce the risk of SUD, aid withdrawal, and reduce the risk of relapse. For example, Novelle [141] concluded that food addiction has many similarities to SUD and that food addiction can be caused by a dysbiotic microbiome. Agustí et al. [142] in a study in rats found that the probiotic Bacteroides uniformis CECT 7771 modifies the brain reward response in such a way as to positively impact binge eating disorder. In a mouse study, Thomaz et al. [143] found that withdrawal of morphine-addicted mice from the drug was aided by manipulation of the gut microbiome.

The tobacco smoking-nicotine-cycle has been shown to be intimately connected to microbiome status [144]. For example, a recent study established that there is specific microbiome-based signature in human blood that identifies and distinguishes former and current smokers [145]. Other research groups found that former and current cigarette smokers could be distinguished from never smokers based on fecal microbiota [146]. Additionally, it was shown that individuals with substance use disorders including nicotine addiction can be distinguished from healthy (non-addicted) controls by their oral microbiome [147]. In another study both smokers and users of smokeless tobacco had oral microbiomes that were distinct from those of healthy controls [148]. The microbiome appears to be particularly sensitive to cigarette smoke. In an experiment in mice using third hand exposure (via a cloth exposed to cigarette smoke), mice exhibited differential age dependent effects. The early postnatal period was the most sensitive resulting in not only significant long-term differences in microbiome composition but also important microbial metabolic changes. For example, third hand exposed mice were significantly elevated in degradation pathways that regulate glycolysis and pyruvate decarboxylation and decreased in coenzyme A biosynthesis and pyrimidine deoxyribonucleoside salvage pathways [149]. Similar effects on the microbiome of children were reported following third hand smoke exposure [150].

Because there is a major shift in human gut microbiome composition with smoking cessation, it has been suggested that the appetite-food consumption-weight gain side effect of smoking cessation is likely to be microbiota driven [151]. The likelihood of weight gain upon smoking cessation is an ongoing impediment to smoking cessation [152].

Finally, a study in rats by Simpson et al. [153] provided additional support for microbiome status to be considered first and foremost when it comes to addiction-withdrawal issues. The researchers found that depletion of the gut microbiome caused recruitment/expansion of the same neuronal ensembles across several regions that are involved in both the intoxication to and the withdrawal from oxycodone. The investigators stressed 
that microbiome status and metabolism are critical when considering responses to substances of abuse including alcohol and nicotine. If the WHO expects to turn their prolonged failure to stop the NCD epidemic into a success, they will have to work through and with the human microbiome.

\section{WHO's Behavioral Modification \#4: Stop the Inactive Lifestyle and Exercise More - (In Spite the Inherent Nature of NCDs)}

This WHO behavioral modification initiative to increase exercise is a good general adjunct to support health. Maintaining fitness during aging is useful as part of an overall health program [154]. In specific examples, dancing has been shown to be neuroprotective with aging because it is beneficial in terms of neuroplasticity [155]. Dancing can improve motor impairments, non-motor skills, and quality of life in both Parkinson's disease patients [156] and those with Alzheimer's disease [157]. Exercise can reduce cardiovascular risk and improve quality of life in cardiovascular patients [158]. It can also improve the disease management of adolescent obesity [159]. These are all very useful life course interventions.

However, the reliance on exercise to prevent and cure NCDs and thereby stop the NCD epidemic is a questionable approach. While exercise is useful, it is important to recognize its limitations as per the eliminating NCDs. Exercise does not correct core microimmunosome issues creating the misregulated inflammation required for NCDs to exist/persist. Leaving the actual systems biology defects that cause and maintain NCDs fully in place in the population while expending global public health resources to pursue healthful, yet peripherally-relevant, incomplete approaches to the NCD epidemic is, in the end, a net public disservice. It is important to note that once children are diagnosed with a NCD like asthma or obesity, double digit comorbidities will follow as the cohort ages [9]. This is problematic for ease of exercise beginning even in childhood. In 2016 the WHO published a report recognizing that NCDs have accompanying disabilities including physical limitations [160]. It is better never to start down the path of life-long ever increasing NCDs.

In fact if exercise where the complete route to stopping the NCD epidemic, then the WHO should be promoting ready microbiome-based strategies to gain the most out of exercise. For example, Lee et al. [161] showed that a single probiotic bacterium, human origin Lactobacillus plantarum PL-02 (obtained from the intestines of 2008 Olympic women's $48 \mathrm{~kg}$ weightlifting gold medalist) 4-week supplementation could significantly increase muscle mass, muscle strength, endurance performance, and hepatic and muscular glycogen storage, while significantly decreasing lactate, blood urea nitrogen, ammonia, and creatine kinase. The take home message is that the microbiome should be included rather than excluded in virtually any initiative intended to benefit public health. Singlespecies humans do not now and probably never did exist. Public Health Institutions need to program and prioritize for the $21^{\text {st }}$ century reality of humans as holobionts.

Beside the fact that the WHO's exercise program does not go after the core causes and system biology defects propagating NCDs, it can be argued that the exercise program is also incomplete because it is too late in light of known developmental and transgenerational epigenetic programming of NCDs. As will be discussed in the following section, the reality is that early life is the window during which most NCDs become programmed within the life course $[162,163]$. 


\subsection{Early-life Programming of NCDs vs. Exercise}

While exercise is a healthful pursuit as previously described, there is problematic reality mentioned earlier for Public Health entities like the WHO that are touting exercise as the conqueror of the NCD epidemic. The problem is the 1990soriginated science originally known as the Barker Hypothesis and later termed DOHaD. The Barker Hypothesis originally described more than 30 years ago by British physician/researcher D.J. Barker, states that fetal and infant conditions can program for later life adult cardiovascular disease [164]. As more researchers examined this hypothesis, the windows of vulnerability for disease programming were expanded to include portions of childhood [56]. The number of diseases that can be programmed in early life expanded exponentially to include virtually all NCDs.

A decade ago, Hanson and Glickman [165] called for a shift in public health policy to reflect the reality of early-life programming of the world's number one killer, NCDs. However, there is little evidence to indicate that this shift in focus has actually happened. Certainly, the WHO's four pillars to defeat the NCD epidemic (including exercise) does not seem to be oriented toward fetal and infant development.

\subsection{Priority of the Microbiome and The First 1,000 Days Concept}

With the discovery of the importance of the microbiome for programmed development of the baby's physiological systems (including the immune system) an even greater concern has arisen to protect and nurture early life of the human superorganism as the way to stop the NCD epidemic. The Barker Hypothesis, DOHaD, and the microbiome's impact in early life was discussed previously by Dietert [9] in the preceding Microbiome First Medicine paper in this journal. The point was stressed that several key microbiome seeding- and feeding-related events must occur to rebalance the fetal immune system and prevent immune inflammation-inflicted NCDs as ageing occurs. Here, it is important to note the Public Health's combined lack of priority for microbiome-aided infant development and correction of "regulatory gaps" in safety for the fetus and infant has done more to fuel the ongoing NCD epidemic than to bring it to an end.

With the microbiome added into $\mathrm{DOHaD}$, the concept of a new overarching critical window of vulnerability has emerged: the First 1,000 Days of a baby's life (fetal and neonatal). During the perinatal period of infant development starting with issues of pregnancy, mode of delivery, antibiotics, colostrum, and breastfeeding, there is a critical need to manage both mom's and baby's microbes. Simply put, the evidence suggests that public health attention to the whole superorganism is needed and the most gain in health protection and life-long health benefits per medical and the public health efforts is during a period of infant microbe-physiological programming that spans approximately the first 1,000 days of a baby's life [166-168].

Several pediatric-related groups and organizations have described the plasticity of the infant's first 1,000 days and called upon public health to make this the highest priority to prevent NCDs [169-172]. However, it is critical that the focus is not simply on the period of infant development. Focus should also be directed toward the microbiome, its impact on systems biology development, such as with the microbioimmunosome, the gutimmune-brain-axis, and the gut-bile salt metabolism interactions [9], as well as superorganism safety from toxic drugs, foods, food additives, and environmental chemicals. The First 1,000 Days focus is useful but only if it is human superorganism wide. Public health institutions like the WHO, FDA, NIH, EPA, USDA, CDC and their equivalents in other countries need to refocus their NCD epidemic-fighting priorities to where our current science indicates it would be most effective: on the microbiome, 
particularly in early life. That is a path where public health can reverse its lengthy legacy of failures (Table 1).

\section{Conclusions}

By many accounts, public health organizations and institutions have taken a glorious beginning and turned it into a lengthy series of failures over the past half century. Organizations like the WHO have recognized that NCDs are the world's number one killer and that an NCD epidemic has been raging for decades. Yet, despite public health initiatives, the numbers indicate that the epidemic is still raging unabated. This pattern of failure is understandable since public health priorities have been slow to embrace the overriding importance of the microbiome and the reality that: 1 ) many NCDs are programmed in early life, and 2) NCDs begin to emerge during childhood (e.g., childhood asthma, obesity) [9]. The four pillars for fighting the NCDs chastises the public for poor nutrition, addictive behaviors, and inactivity. They stress that behavioral modification is the solution to our NCD epidemic [13]. This current review illustrates that this initiative is doomed to failure because it fails to include the need to manage the microbiome to readily change diet and withdrawal from food, drug, and chemical addiction. Chastising the public without providing critical microbiome-based education and tools required for individuals to pursue a healthy life is not a path to success regarding NCDs. At the same time an effort is needed to remove microbiome-damaging foods, drugs, food additives, and chemicals from our cities, store shelves, and households. Our past sins of not identifying and/or removing hazards for the human superorganism need to be corrected. The goal is not to damage the microbiome during pregnancy and the first 1,000 days of infant development. Instead, it is to support mother and child beginning first and foremost with the majority of their cells and genes, the human microbiome.

Funding: The research and preparation for this review article received no external funding.

Acknowledgments: The author thanks Janice Dietert for providing editorial support.

Conflicts of Interest: The author declares that he provided general educational support to a probiotics company and an infant health company. The companies had no role in the content or preparation of this review article. No products or services of these companies were discussed in this review article. 


\section{References}

1. Duffy, J. The Sanitarians: A History of American Public Health, $1^{\text {st }}$ ed.; University of Illinois Press: Champaign, IL, USA 1992. 344pp. ISBN-13: 9780252062766

2. Cranor, C.F. Tragic Failures: How and Why We are Harmed by Toxic Chemicals, 1st ed.; Oxford University Press: Oxford UK 2017. 264pp. ISBN-13: 978-0190635756

3. Editors. The catastrophic failures of public health. Lancet 2004, 363(9411):745. doi: 10.1016/S0140-6736(04)15712-7.

4. Bellinger, D.C. Lead Contamination in Flint--An Abject Failure to Protect Public Health. N Engl J Med 2016, 374(12):1101-1103. doi: 10.1056/NEJMp1601013.

5. Maffini, M.V.; Neltner, T.G.; Vogel. S. We are what we eat: Regulatory gaps in the United States that put our health at risk. PLoS Biol 2017, 15, e2003578. doi:10.1371/journal.pbio.2003578

6. Myers, J.P.; Antoniou, M.N.; Blumberg. B.; Carroll. L.; Colborn, T.; Everett, L.G.; Hansen, M.; Landrigan, P.J.; Lanphear, B.P.; Mesnage, R. et al. Concerns over use of glyphosate-based herbicides and risks associated with exposures: a consensus statement. Environ Health 2016, 15, 19. doi: 10.1186/s12940-016-0117-0.

7. Lobstein, T.; Brownell, K.D. Endocrine-disrupting chemicals and obesity risk: A review of recommendations for obesity prevention policies. Obes Rev 2021, Aug 18. doi: 10.1111/obr.13332.

8. Wilkinson, J.E.; Franzosa, E.A.; Everett, C.; Li, C.; HCMPH researchers and trainees; HCMPH investigators; Hu, F.B.; Wirth, D.F.; Song, M.; Chan, A.T. et al. A framework for microbiome science in public health. Nat Med 2021, 27, 766774 https://doi.org/10.1038/s41591-021-01258-0

9. Dietert, R.R. Microbiome First Medicine in Health and Safety. Biomedicines 2021, 9(9): 1099. doi: 10.3390/biomedicines9091099.

10. King, D.E.; Xiang, J.; Pilkerton, C.S. Multimorbidity Trends in United States Adults, 1988-2014. J Am Board Fam Med 2018, 31(4), 503-513. doi: 10.3122/jabfm.2018.04.180008.

11. Bloom, D.E.; Cafiero, E.T.; Jané-Llopis, E.; Abrahams-Gessel, S.; Bloom, L.R.; Fathima, S.; Feigl, B.; Gaziano, T.; Mowafi, M.; Pandya, A. et al. The Global Economic Burden of Noncommunicable Diseases. 2011, World Economic Forum: Geneva, Switzerland 48pp.

12. World Health Organization. Noncommunicable Diseases Fact Sheet. 21 April 2021, World Health Organization: Geneva, Switzerland https://www.who.int/news-room/fact-sheets/detail/noncommunicable-diseases (accessed August 27, 2021) 
13. World Health Organization. Preventing noncommunicable diseases. https://www.who.int/activities/preventing-noncommunicable-diseases (Accessed 27 August, 2021).

14. Newsholme, A. The possible association of the consumption of alcohol with excessive mortality from cancer. $\mathrm{Br} \mathrm{Med} J$ 1903, 2(2241):1529-1531. doi: 10.1136/bmj.2.2241.1529.

15. The Tobacco Heart. Hospital (London). 1901, 30(758): 6. https://www.ncbi.nlm.nih.gov/pmc/articles/PMC5186887/?page=1

16. Foxcroft, L. Calories and Corsets: A history of dieting over two thousand years. Profile Books: London, UK 2012320 pp. ISBN: 978-1846684258

17. Tipton, C.M. The history of "Exercise Is Medicine" in ancient civilizations. Adv Physiol Educ 2014, 38(2): 109-117. doi:10.1152/advan.00136.2013

18. Franklin, B. III. Dialog Between Franklin and the Gout. Essays, Midnight, 22 October, 1780. In Matthews, B. The Oxford Book of American Essays. Oxford University Press: New York, NY, USA 1914. 508 pp.; Online published, 2000 https://www.bartleby.com/109/3.html (accessed Oct. 9, 2021)

19. GBD 2019; Risk Factors Collaborators 2020. Global burden of 87 risk factors in 204 countries and territories, 19902019: a systematic analysis for the Global Burden of Disease Study 2019. Lancet 2020, 396, 1223-1249. https://doi.org/10.1016/S0140-6736(20)30752-2

20. Dean, E.; Skinner. M; Yu, H.P.; Jones, A.Y.; Gosselink, R.; Söderlund, A. Why COVID-19 strengthens the case to scale up assault on non-communicable diseases: role of health professionals including physical therapists in mitigating pandemic waves. AIMS Public Health 2021, 8, 369-375. doi: 10.3934/publichealth.2021028.

21. Dietert, R.R. Lessons for human holobiont medicine in the era of SARS-Cov-2. Am J Biomed Sci Res 2021, 13, 152-156. doi: 10.34297/AJBSR.2021.13.001849 https://biomedgrid.com/fulltext/volume13/lessons-for-human-holobiont-medicine-in-the-era-of-sars-cov-2.001849.php

22. Chan, E.Y.Y.; Kim, J.H.1 Lo, E.S.K.; Huang, Z.; Hung, H.; Hung, K.K.C.; Wong, E.L.Y.; Lee, E.K.P.; Wong, M.C.S.; Wong, S.Y.S. What Happened to People with Non-Communicable Diseases during COVID-19: Implications of HEDRM Policies. Int J Environ Res Public Health 2020, 17, 5588. doi: 10.3390/ijerph17155588.

23. Finlay, B.B.; Amato, K.R.; Azad, M.; Blaser, M.J.; Bosch, T.C.G.; Chu, H.; Dominguez-Bello, M.G.; Ehrlich, S.D.; Elinav, E.; Geva-Zatorsky, N. et al. The hygiene hypothesis, the COVID pandemic, and consequences for the human microbiome. Proc Natl Acad Sci U S A 2021, 118, e2010217118. doi: 10.1073/pnas.2010217118. 
24. Dietert, R.R. The microbiological basis of human superorganism freedom. Am J Biomed Sci Res 2021, 13, 653-662. doi: 10.34297/AJBSR.2021.13.001933.

25. Office of the Director - Eunice Kennedy Shriver National Institute of Child Health and Human Development. National Children's Study Archive (version 5/12/20). https://www.nichd.nih.gov/research/supported/NCS (accessed August 26, 2021)

26. Hudak, M.L.; Park, C.H.; Annett, R.D.; Hale, D.E.; McGovern, P.M.; McLaughlin, T.J.; Dole, N.; Kaar, J.L.; Balsam, M.J. The National Children's Study: An Introduction and Historical Overview. Pediatrics 2016, 137, S213-218. doi: 10.1542/peds.2015-4410B.

27. Kaiser, J. NIH cancels massive U.S. children's study. Science 12 Dec. 2014, doi: 10.1126/article.71640 https://www.science.org/news/2014/12/nih-cancels-massive-us-children-s-study (accessed August 27, 2021)

28. Schmidt, C. The Death of the National Children's Study: What Went Wrong? Undark May 25, 2016. https://undark.org/2016/05/25/the-death-of-a-study-national-childrens-study/ (accessed August 30, 2021)

29. Greenstreet, R. Adjustment of rates of Guillain-Barré syndrome among recipients of swine flu vaccine, 1976-1977. J R Soc Med 1983, 76, 620-621. https://www.ncbi.nlm.nih.gov/pmc/articles/PMC1439115/

30. Sencer, D.J.; Millar, J.D. Reflections on the 1976 swine flu vaccination program. Emerg Infect Dis 2006, 12, 29-33. doi:10.3201/eid1201.051007

31. Arachi, D.; Furuya, S.; David, A.; Mangwiro, A.; Chimed-Ochir, O.; Lee, K.; Tighe, P.; Takala, J.; Driscoll, T.; Takahashi, K. Development of the "National Asbestos Profile" to Eliminate Asbestos-Related Diseases in 195 Countries. Int J Environ Res Public Health 2021, 18, 1804. doi: 10.3390/ijerph18041804.

32. Banerjee, N.; Wang, H.; Wang, G; Boor, P.J.; Khan, M.F. Redox-sensitive Nrf2 and MAPK signaling pathways contribute to trichloroethene-mediated autoimmune disease progression. Toxicology 2021, 457, 152804. doi: 10.1016/j.tox.2021.152804.

33. Ben Maamar, M.; Nilssonm E.; Thorson, J.L.M.; Beck, D.; Skinner, M.K. Transgenerational disease specific epigenetic sperm biomarkers after ancestral exposure to dioxin. Environ Res 2021, 192, 110279. doi: 10.1016/j.envres.2020.110279.

34. McCann, M.S.; Fernandez, H.R.; Flowers, S.A.; Maguire-Zeiss, K.A. Polychlorinated biphenyls induce oxidative stress and metabolic responses in astrocytes. Neurotoxicology 2021, 86, 59-68. doi: 10.1016/j.neuro.2021.07.001. 
35. Pirozzi, C.; Lama, A.; Annunziata, C.; Cavaliere, G.; Ruiz-Fernandez, C.; Monnolo, A.; Comella, F.; Gualillo, O.; Stornaiuolo, M.; Mollica, M.P. et al. Oral Bisphenol A Worsens Liver Immune-Metabolic and Mitochondrial Dysfunction Induced by High-Fat Diet in Adult Mice: Cross-Talk between Oxidative Stress and Inflammasome Pathway. Antioxidants (Basel) 2020, 9, 1201. doi: 10.3390/antiox9121201.

36. Pandey, N.; Maske, P.; Mote, C.; Dighe, V. Exposure to Atrazine through gestation and lactation period led to impaired sexual maturation and subfertility in F1 male rats with congenital deformities in F2 progeny. Food Chem Toxicol 2021, 29, 112586. doi: 10.1016/j.fct.2021.112586.

37. Wang, D.; Liu, J.; Jiang, H. Triclosan regulates the Nrf2/HO-1 pathway through the PI3K/Akt/JNK signaling cascade to induce oxidative damage in neurons. Environ Toxicol 2021, 36, 1953-1964. doi: 10.1002/tox.23315.

38. Qiu, L.; Wang, H.; Dong, T.; Huang, J.; Li, T.; Ren, H.; Wang, X.; Qu, J.; Wang, S. Perfluorooctane sulfonate (PFOS) disrupts testosterone biosynthesis via CREB/CRTC2/StAR signaling pathway in Leydig cells. Toxicology 2021, 449, 152663. doi: 10.1016/j.tox.2020.152663.

39. Kannan, K.; Vimalkuma,r K. A Review of Human Exposure to Microplastics and Insights Into Microplastics as Obesogens. Front Endocrinol (Lausanne) 2021, 12, 724989. doi: 10.3389/fendo.2021.724989.

40. Chen, L.; Nie, P.; Yao, L.; Tang, Y.; Hong, W.; Liu, W.; Fu, F.; Xu, H. TiO2 NPs induce the reproductive toxicity in mice with gestational diabetes mellitus through the effects on the endoplasmic reticulum stress signaling pathway. Ecotoxicol Environ Saf 2021, 226, 112814. doi: 10.1016/j.ecoenv.2021.112814.

41. Hu, J., Lesseur, C., Miao, Y.; Manservisi, F.; Panzacchi, S.; Mandrioli, D.; Belpoggi, F.; Chen, J.; Petrick, L. Low-dose exposure of glyphosate-based herbicides disrupt the urine metabolome and its interaction with gut microbiota. Sci Rep 2021, 11, 3265. https://doi.org/10.1038/s41598-021-82552-2

42. Le Bastard, Q.; Berthelot, L.; Soulillou, J.P.; Montassier, E. Impact of non-antibiotic drugs on the human intestinal microbiome. Expert Rev Mol Diagn 2021, 15, 1-14. doi: 10.1080/14737159.2021.1952075.

43. Wang, X.; Tang, Q.; Hou, H.; Zhang, W.; Li, M.; Chen, D.; Gu, Y.; Wang, B.; Hou, J.; Liu, Y.; Cao, H. Gut Microbiota in NSAID Enteropathy: New Insights From Inside. Front Cell Infect Microbiol 2021, 11, 679396. doi: 10.3389/fcimb.2021.679396.

44. Inghammar, M; Svanström, H.; Voldstedlund, M.; Melbye, M.; Hviid, A.; Mølbak, K.; Pasterna, B. Proton-Pump Inhibitor Use and the Risk of Community-Associated Clostridium difficile Infection. Clin Infect Dis 2021, 72, e1084e1089. doi: 10.1093/cid/ciaa1857. 
45. Bancil, A.S.; Sandall, A.M.; Rossi, M.; Chassaing, B.; Lindsay, J.O.; Whelan, K. Food Additive Emulsifiers and Their Impact on Gut Microbiome, Permeability, and Inflammation: Mechanistic Insights in Inflammatory Bowel Disease. J Crohns Colitis 2021, 15, 1068-1079. doi: 10.1093/ecco-jcc/jjaa254.

46. Naimi, S.; Viennois, E.; Gewirtz, A.T.; Chassaing, B. Direct impact of commonly used dietary emulsifiers on human gut microbiota. Microbiome 2021, 9, 66. doi: 10.1186/s40168-020-00996-6.

47. Jin, G.; Tang, Q.; Ma, J.; Liu, X.; Zhou, B.; Sun, Y.; Pang, X.; Guo, Z.; Xie, R.; Liu, T.; Wang, B.; Cao, H. Maternal Emulsifier P80 Intake Induces Gut Dysbiosis in Offspring and Increases Their Susceptibility to Colitis in Adulthood. mSystems 2021, 6, e01337-20. doi: 10.1128/mSystems.01337-20.

48. Latham, J. The failure of the genome. The Guardian (UK) 2011 (April 17), https://www.theguardian.com/commentisfree/2011/apr/17/human-genome-genetics-twin-studies

49. DeWitt, R.D. Pediatric lead exposure and the water crisis in Flint, Michigan. JAAPA 2017, 30, 43-46. doi: 10.1097/01.JAA.0000511794.60054.eb.

50. Hanna-Attisha, M.; Lanphear, B.; Landrigan, P. Lead Poisoning in the 21st Century: The Silent Epidemic Continues. Am J Public Health 2018, 108, 1430. doi: 10.2105/AJPH.2018.304725.

51. Block, J. Vaccinating people who have had covid-19: why doesn't natural immunity count in the US? BMJ 2021, 374, n2101. doi: 10.1136/bmj.n2101.

52. Bejarano, D.A.; Schlitzer, A. Breathing more breadth into COVID-19 T cell responses. Med (N Y) 2021, 2, 999-1001. doi:10.1016/j.medj.2021.08.009

53. CDC statement. Natural immunity and vaccinations. CDC Media Relations. 2021 (August 6), https://www.cdc.gov/me-

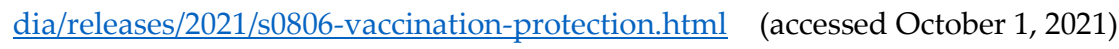

54. Zabetakis, I.; Lordan, R.; Norton, C.; Tsoupras, A. COVID-19: The Inflammation Link and the Role of Nutrition in Potential Mitigation. Nutrients 2020, 12, 1466. doi: 10.3390/nu12051466.

55. Nikoloski, Z.; Alqunaibet, A.M.; Alfawaz, R.A.; Almudarra, S.S.; Herbst, C.H.; El-Saharty, S.; Alsukait, R.; Algwizani, A. Covid-19 and non-communicable diseases: evidence from a systematic literature review. BMC Public Health 2021, 21, 1068. doi: 10.1186/s12889-021-11116-w.

56. Dietert, R.R.; Etzel, R.A.; Chen, D.; Halonen, M.; Holladay, S.D.; Jarabek, A.M.; Landreth, K.; Peden, D.B.; Pinkerton, K.; Smialowicz, R.J.; Zoetis, T. Workshop to identify critical windows of exposure for children's health: immune and respiratory systems work group summary. Environ Health Perspect 2000, 108, 483-490. doi: 10.1289/ehp.00108s3483. 
57. Barouki, R.; Gluckman, P.D.; Grandjean, P.; Hanson, M.; Heindel, J.J. Developmental origins of non-communicable disease: implications for research and public health. Environ Health 2012, 11, 42. doi: 10.1186/1476-069X-11-42.

58. Anway, M.D.; Skinner, M.K. Epigenetic transgenerational actions of endocrine disruptors. Endocrinology 2006, 147, S43-49. doi: 10.1210/en.2005-1058.

59. George, F.; Mahieux, S.; Daniel, C.; Titécat, M.; Beauval, N.; Houcke, I.; Neut, C.; Allorge, D.; Borges, F.; Jan, G. et al. Assessment of $\mathrm{Pb}(\mathrm{II}), \mathrm{Cd}(\mathrm{II})$, and $\mathrm{Al}(\mathrm{III})$ Removal Capacity of Bacteria from Food and Gut Ecological Niches: Insights into Biodiversity to Limit Intestinal Biodisponibility of Toxic Metals. Microorganisms 2021, 9, 456. doi: 10.3390/microorganisms9020456.

60. Duan, H.; Yu, L.; Tian, F.; Zhai, Q.; Fan, L.; Chen, W. Gut microbiota: A target for heavy metal toxicity and a probiotic protective strategy. Sci Total Environ 2020, 742, 140429. doi: 10.1016/j.scitotenv.2020.140429.

61. Su, H.; Liu, J.; Wu, G.; Long, Z.; Fan, J.; Xu, Z.; Liu, J.; Yu, Z.; Cao, M.; Liao, N. et al. Homeostasis of gut microbiota protects against polychlorinated biphenyl 126-induced metabolic dysfunction in liver of mice. Sci Total Environ 2020, 720, 137597. doi: 10.1016/j.scitotenv.2020.137597.

62. Yu, L.; Zhang, L.; Duan, H.; Zhao, R.; Xiao, Y.; Guo, M.; Zhao, J.; Zhang, H.; Chen, W., Tian, F. The Protection of Lactiplantibacillus plantarum CCFM8661 Against Benzopyrene-Induced Toxicity via Regulation of the Gut Microbiota. Front Immunol 2021, 12, 736129. doi: 10.3389/fimmu.2021.736129.

63. Dietert, R.R.; Dietert, J.M. Twentieth Century Dogmas Prevent Sustainable Healthcare. Am J Biomed Sci and Res 2021, 13,409-417. doi: 10.34297/AJBSR.2021.13.001890.

64. Cani, P.D.; Everard, A. Keeping gut lining at bay: impact of emulsifiers. Trends Endocrinol Metab 2015 26, 273-274. doi: 10.1016/j.tem.2015.03.009.

65. Jiang, Z.; Zhao, M.; Zhang, H.; Li, Y.; Liu, M.; Feng, F. Antimicrobial Emulsifier-Glycerol Monolaurate Induces Metabolic Syndrome, Gut Microbiota Dysbiosis, and Systemic Low-Grade Inflammation in Low-Fat Diet Fed Mice. Mol Nutr Food Res 2018, 62(3). doi: 10.1002/mnfr.201700547.

66. Godinez Puig, L.; Lusk, K.; Glick, D.; Einstein, K.L.; Palmer, M.; Fox, S.; Wang, M.L. Perceptions of Public Health Priorities and Accountability Among US Mayors. Public Health Rep 2021, 136, 161-171. doi: 10.1177/0033354920966050.

67. WHO Obesity and Overweight. Fact Sheet. Online published 9 June 2021. https://www.who.int/news-room/factsheets/detail/obesity-and-overweight (accessed October 9, 2021) 
68. Vogel, S.A. The politics of plastics: the making and unmaking of bisphenol a "safety". Am J Public Health 2009, 99, S559-S566. doi:10.2105/AJPH.2008.159228

69. Andújar, N.; Gálvez-Ontiveros, Y.; Zafra-Gómez, A.; Rodrigo, L.; Álvarez-Cubero, M.J.; Aguilera, M.; Monteagudo, C.; Rivas, A.A. Bisphenol A Analogues in Food and Their Hormonal and Obesogenic Effects: A Review. Nutrients 2019, 11, 2136. doi: 10.3390/nu11092136.

70. Desai, M.; Ferrini, M.G.; Jellyman, J.K.; Han, G.; Ross, M.G. In vivo and in vitro bisphenol A exposure effects on adiposity. J Dev Orig Health Dis 2018, 9, 678-687. doi: 10.1017/S2040174418000600.

71. Pérez-Bermejo, M.; Mas-Pérez, I.; Murillo-Llorente, M.T. The Role of the Bisphenol A in Diabetes and Obesity. Biomedicines 2021, 9, 666. doi: 10.3390/biomedicines9060666.

72. Linares, R.; Fernández, M.F.; Gutiérrez, A.; García-Villalba, R.; Suárez, B.; Zapater, P.; Martínez-Blázquez, J.A.; Caparrós, E.; Tomás-Barberán, F.A.; Francés, R. Endocrine disruption in Crohn's disease: Bisphenol A enhances systemic inflammatory response in patients with gut barrier translocation of dysbiotic microbiota products. FASEB J 2021, 35, e21697. doi: 10.1096/fj.202100481R.

73. Roberts, L. Genome Mapping Goal Now in Reach: James Watson has promised to complete a map of the human genome within 5 years; now it looks like it might be doable. Science 1989, 244, 424-425. DOI: 10.1126/science.2717935

74. Anderson, G.C. Human genome project. The honeymoon is over. Nature 1990 346, 309. doi: 10.1038/346309a0.

75. Saey, T.H. More than a chicken, fewer than a grape. Science News 2010 (Oct. 13) https://www.sciencenews.org/article/more-chicken-fewer-grape (accessed October 11, 2021).

76. Craft-Blacksheare, M.G. Lessons Learned From the Crisis in Flint, Michigan Regarding the Effects of Contaminated Water on Maternal and Child Health. J Obstet Gynecol Neonatal Nurs 2017 46, 258-266. doi: 10.1016/j.jogn.2016.10.012.

77. Akdis, C.A. Does the epithelial barrier hypothesis explain the increase in allergy, autoimmunity and other chronic conditions? Nat Rev Immunol 2021 Apr 12. doi: 10.1038/s41577-021-00538-7.

78. Swaney, M.H.; Kalan, L.R. Living in Your Skin: Microbes, Molecules, and Mechanisms. Infect Immun 2021, 89, e0069520. doi: 10.1128/IAI.00695-20.

79. Nakatsuji, T.; Chen, T.H.; Narala, S.; Chun, K.A.; Two, A.M.; Yun, T.; Shafiq, F.; Kotol, P.F.; Bouslimani, A.; Melnik, A.V. et al. Antimicrobials from human skin commensal bacteria protect against Staphylococcus aureus and are deficient in atopic dermatitis. Sci Transl Med 2017, 9, eaah4680. doi: 10.1126/scitranslmed.aah4680. 
80. Tan-Lim, C.S.C.; Esteban-Ipac, N.A.R.; Recto, M.S.T.; Castor, M.A.R.; Casis-Hao, R.J.; Nano, A.L.M. Comparative effectiveness of probiotic strains on the prevention of pediatric atopic dermatitis: A systematic review and network meta-analysis. Pediatr Allergy Immunol 2021, 32, 1255-1270. doi: 10.1111/pai.13514.

81. Cukrowska, B.; Ceregra, A.; Maciorkowska, E.; Surowska, B.; Zegadło-Mylik, M.A.; Konopka, E.; Trojanowska, I.; Zakrzewska, M.; Bierła, J.B.; Zakrzewski, M. et al. The Effectiveness of Probiotic Lactobacillus rhamnosus and Lactobacillus casei Strains in Children with Atopic Dermatitis and Cow's Milk Protein Allergy: A Multicenter, Randomized, Double Blind, Placebo Controlled Study. Nutrients 2021, 13, 1169. doi: 10.3390/nu13041169.

82. Callewaert, C.; Knödlseder, N.; Karoglan, A.; Güel,1 M.; Paetzold ,B. Skin microbiome transplantation and manipulation: Current state of the art. Comput Struct Biotechnol J 2021, 19, 624-631. doi:10.1016/j.csbj.2021.01.001

83. Abuqwider, J.N.; Mauriello, G.; Altamimi, M. Akkermansia muciniphila, a New Generation of Beneficial Microbiota in Modulating Obesity: A Systematic Review. Microorganisms 2021, 9, 1098. https://doi.org/10.3390/microorgan$\underline{\text { isms } 9051098}$

84. Ouyang, J.; Lin, J.; Isnard, S.; Fombuena, B.; Peng, X.; Marette, A.; Routy, B.; Messaoudene, M.; Chen, Y.; Routy, J.P. The Bacterium Akkermansia muciniphila: A Sentinel for Gut Permeability and Its Relevance to HIV-Related Inflammation. Front Immunol 2020, 11, 645. doi: 10.3389/fimmu.2020.00645.

85. Ottman, N.; Reunanen, J.; Meijerink, M.; Pietilä, T.E.; Kainulainen, V.; Klievink, J.; Huuskonen, L.; Aalvink, S.; Skurnik, M.; Boeren, S. et al. Pili-like proteins of Akkermansia muciniphila modulate host immune responses and gut barrier function. PLoS One 2017, 12, e0173004. doi: 10.1371/journal.pone.0173004.

86. Anhê, F.F.; Pilon. G.; Roy, D.; Desjardins, Y.; Levy, E.; Marette, A. Triggering Akkermansia with dietary polyphenols: A new weapon to combat the metabolic syndrome? Gut Microbes 2016, 7, 146-153. doi: 10.1080/19490976.2016.1142036. Erratum in: doi: 10.1136/gutjnl-2014-307142.

87. Huang, D.; Gao, J.; Li, C.; Nong, C.; Huang, W.; Zheng, X.; Li, S.; Peng, Y. A potential probiotic bacterium for antipsychotic-induced metabolic syndrome: mechanisms underpinning how Akkermansia muciniphila subtype improves olanzapine-induced glucose homeostasis in mice. Psychopharmacology (Berl) 2021, 238, 2543-2553. doi: 10.1007/s00213021-05878-9.

88. Carlier, F.M.; de Fays, C.; Pilette, C. Epithelial Barrier Dysfunction in Chronic Respiratory Diseases. Front Physiol 2021, 12, 691227. doi: 10.3389/fphys.2021.691227.

89. Nino, G.; Rodriguez-Martinez, C.E.; Gutierrez, M.J. Early Microbial-Immune Interactions and Innate Immune Training of the Respiratory System during Health and Disease. Children (Basel) 2021, 8, 413. doi: 10.3390/children8050413. 
90. Coleman, M.; Dietert, R.R.; North, D.W.; Stephenson, M.M. Enhancing Human Superorganism Ecosystem Resilience by Holistically 'Managing our Microbes.' J Appl Microbiol 2021 in press.

91. Nordengrün, M.; Abdurrahman, G.; Treffon, J.; Wächter, H.; Kahl, B.C.; Bröker, B.M. Allergic Reactions to Serine Protease-Like Proteins of Staphylococcus aureus. Front Immunol 2021, 12, 651060. doi: 10.3389/fimmu.2021.651060.

92. Lokken-Toyli, K.L.; de Steenhuijsen Piters, W.A.A.; Zangari, T.; Martel, R.; Kuipers, K.; Shopsin, B.; Loomis, C.; Bogaert, D.; Weiser, J.N. Decreased production of epithelial-derived antimicrobial molecules at mucosal barriers during early life. Mucosal Immunol 2021, Aug 31. doi: 10.1038/s41385-021-00438-y.

93. Cole, A.L.; Sundar, M.; Lopez, A.; Forsman, A.; Yooseph, S.; Cole, A.M. Identification of Nasal Gammaproteobacteria with Potent Activity against Staphylococcus aureus: Novel Insights into the "Noncarrier" State. mSphere 2021, 6, e01015-20. doi: 10.1128/mSphere.01015-20.

94. Accorsi, E.K.; Franzosa, E.A.; Hsu, T.; Joice Cordy, R.; Maayan-Metzger, A.; Jaber, H.; Reiss-Mandel, A.; Kline, M.; DuLong, C.; Lipsitch, M. et al. Determinants of Staphylococcus aureus carriage in the developing infant nasal microbiome. Genome Biol 2020, 21, 301. doi: 10.1186/s13059-020-02209-7.

95. Liu, Q.; Liu, Q.; Meng, H.; Lv, H.; Liu, Y.; Liu, J.; Wang, H.; He, L.; Qin, J.; Wang, Y.; Dai, Y.; Otto, M.; Li, M. Staphylococcus epidermidis Contributes to Healthy Maturation of the Nasal Microbiome by Stimulating Antimicrobial Peptide Production. Cell Host Microbe 2020, 27, 68-78. doi: 10.1016/j.chom.2019.11.003.

96. Leung, R.; Covasa, M. Do Gut Microbes Taste?. Nutrients 2021, 13, 2581. doi:10.3390/nu13082581

97. Ellender, G.; Moynihan, P. Oral Health Impacts on Flavor and Significance in Dental Treatment. JDR Clin Trans Res 2021, 15, 2380084421995096. doi: 10.1177/2380084421995096.

98. Jurczak, A.; Jamka-Kasprzyk, M.; Bębenek, Z.; Staszczyk, M.; Jagielski, P.; Kościelniak, D.; Gregorczyk-Maga, I.; Kołodziej, I.; Kępisty, M.; Kukurba-Setkowicz, M. et al. Differences in Sweet Taste Perception and Its Association with the Streptococcus mutans Cariogenic Profile in Preschool Children with Caries. Nutrients 2020, 12, 2592. doi: 10.3390/nu12092592.

99. Burcham, Z.M.; Garneau, N.L.; Comstock, S.S.; Tucker, R.M.; Knight, R.; Metcalf, J.L.; Genetics of Taste Lab Citizen Scientists. Patterns of Oral Microbiota Diversity in Adults and Children: A Crowdsourced Population Study. Sci Rep 2020, 10, 2133. https://doi.org/10.1038/s41598-020-59016-0

100. Li, Y.; Cui, J.; Liu, Y.; Chen, K.; Huang, L.; Liu, Y. Oral, Tongue-Coating Microbiota, and Metabolic Disorders: A Novel Area of Interactive Research. Front Cardiovasc Med 2021, 8, 730203. doi: 10.3389/fcvm.2021.730203. 
101. Esberg, A.; Haworth, S.; Hasslöf, P.; Lif Holgerson, P.; Johansson, I. Oral Microbiota Profile Associates with Sugar Intake and Taste Preference Genes. Nutrients 2020, 12, 681. https://doi.org/10.3390/nu12030681

102. Besnard, P.; Christensen, J.E.; Bernard, A.; Collet, X.; Verges, B.; Burcelin, R. Fatty taste variability in obese subjects: the oral microbiota hypothesis 2020, 27, 38. https://doi.org/10.1051/ocl/2020033

103. Besnard, P., Christensen, J.E., Bernard, A. et al. Identification of an oral microbiota signature associated with an impaired orosensory perception of lipids in insulin-resistant patients. Acta Diabetol 57, 1445-1451 (2020). https://doi.org/10.1007/s00592-020-01567-9

104. Bernard, A.; Le Beyec-Le Bihan, J;, Radoi, L.; Coupaye, M.; Sami, O.; Casanova, N.; Le May, C.; Collet, X.; Delaby, P.; Le Bourgot, C. et al. Orosensory Perception of Fat/Sweet Stimuli and Appetite-Regulating Peptides before and after Sleeve Gastrectomy or Gastric Bypass in Adult Women with Obesity. Nutrients 2021, 13, 878. doi: 10.3390/nu13030878.

105. Khan, A.S.; Keast, R.; Khan, N.A. Preference for dietary fat: From detection to disease. Prog Lipid Res 2020, 78, 101032. doi: 10.1016/j.plipres.2020.101032.

106. Mameli, C.; Cattaneo, C.; Panelli, S.; Comandatore, F.; Sangiorgio, A.; Bedogni, G.; Bandi, C.; Zuccotti, G.; Pagliarini, E. Taste perception and oral microbiota are associated with obesity in children and adolescents. PLoS One 2019, 14, e0221656. doi: 10.1371/journal.pone.0221656.

107. Cattaneo, C.; Riso, P.; Laureati, M.; Gargari, G., Pagliarini, E. Exploring Associations between Interindividual Differences in Taste Perception, Oral Microbiota Composition, and Reported Food Intake. Nutrients 2019, 11, 1167. doi: 10.3390/nu11051167.

108. Pocheron, A.L.; Le Dréan, G.; Billard, H.; Moyon, T.; Pagniez, A.; Heberden, C.; Le Chatelier, E.; Darmaun, D.; Michel, C.; Parnet, P. Maternal Microbiota Transfer Programs Offspring Eating Behavior. Front Microbiol 2021, 12, 672224. doi: 10.3389/fmicb.2021.672224.

109. Bernard, A.; Ancel, D.; Neyrinck, A.M.; Dastugue, A.; Bindels, L.B.; Delzenne, N.M.; Besnard, P. A Preventive Prebiotic Supplementation Improves the Sweet Taste Perception in Diet-Induced Obese Mice. Nutrients 2019, 11, 549. doi: 10.3390/nu11030549.

110. Heys, C.; Fisher, A.M.; Dewhurst, A.D.; Lewis, Z.; Lizé, A. Exposure to foreign gut microbiota can facilitate rapid dietary shifts. Sci Rep 2021, 11, 16791. doi:10.1038/s41598-021-96324-5 
111. Leitão-Gonçalves, R.; Carvalho-Santos, Z.; Francisco, A.P.; Fioreze, G.T.; Anjos, M.; Baltazar, C.; Elias, A.P.; Itskov, P.M.; Piper, M.D.W.; Ribeiro, C. Commensal bacteria and essential amino acids control food choice behavior and reproduction. PLoS Biol 2017, 15, e2000862. doi: 10.1371/journal.pbio.2000862.

112. Schwartz, M.; Canon, F.; Feron, G.; Neiers, F.; Gamero, A. Impact of Oral Microbiota on Flavor Perception: From Food Processing to In-Mouth Metabolization. Foods 2021, 10, 2006. https://doi.org/10.3390/foods10092006

113. Thompson, M.D.; DeBosch, B.J. Maternal Fructose Diet-Induced Developmental Programming. Nutrients 2021, 13, 3278. doi: 10.3390/nu13093278.

114. Beisner, J.; Gonzalez-Granda, A.; Basrai, M.; Damms-Machado, A.; Bischoff, S.C. Fructose-Induced Intestinal Microbiota Shift Following Two Types of Short-Term High-Fructose Dietary Phases. Nutrients 2020, 12, 3444. doi: $10.3390 /$ nu12113444.

115. Naudon, L.; François, A.; Mariadassou, M.; Monnoye, M.; Philippe, C.; Bruneau, A.; Dussauze, M.; Rué, O.; Rabot, S.; Meunier, N. First step of odorant detection in the olfactory epithelium and olfactory preferences differ according to the microbiota profile in mice. Behav Brain Res 2020, 384, 112549. doi: 10.1016/j.bbr.2020.112549.

116. Bienenstock, J.; Kunze, W.A.; Forsythe, P. Disruptive physiology: olfaction and the microbiome-gut-brain axis. Biol Rev Camb Philos Soc 2018, 93, 390-403. doi: 10.1111/brv.12348.

117. Koskinen, K.; Reichert, J.L.; Hoier, S.; Schachenreiter, J.; Duller, S.; Moissl-Eichinger, C.; Schöpf, V. The nasal microbiome mirrors and potentially shapes olfactory function. Sci Rep 2018, 8, 1296. doi: 10.1038/s41598-018-19438-3.

118. Casadei, E.; Tacchi, L.; Lickwar, C.R.; Espenschied, S.T.; Davison, J.M.; Muñoz, P.; Rawls, J.F.; Salinas, I. Commensal Bacteria Regulate Gene Expression and Differentiation in Vertebrate Olfactory Systems Through Transcription Factor REST. Chem Senses 2019, 44, 615-630. doi: 10.1093/chemse/bjz050.

119. Morquecho-Campos, P.; de Graaf, K.; Boesveldt, S. Smelling our appetite? The influence of food odors on congruent appetite, food preferences and intake. Food Qual Preference 2020, 85, 103959. https://doi.org/10.1016/j.foodqual.2020.103959

120. Uauy, R.; Díaz. E. Consequences of food energy excess and positive energy balance. Public Health Nutr 2005, 8, 10771099. doi: 10.1079/phn2005797.

121. Rautmann, A.W.; de La Serre, C.B. Microbiota's Role in Diet-Driven Alterations in Food Intake: Satiety, Energy Balance, and Reward. Nutrients 2021, 13, 3067. doi: 10.3390/nu13093067. 
122. Han, H.; Yi, B.; Zhong, R.; Wang, M.; Zhang, S.; Ma, J.; Yin, Y.; Yin, J.; Chen, L.; Zhang, H. From gut microbiota to host appetite: gut microbiota-derived metabolites as key regulators. Microbiome 2021, 9, 162. doi: 10.1186/s40168-021-01093$\mathrm{y}$.

123. Pizarroso, N.A.; Fuciños, P.; Gonçalves, C.; Pastrana, L.; Amado, .IR. A Review on the Role of Food-Derived Bioactive Molecules and the Microbiota-Gut-Brain Axis in Satiety Regulation. Nutrients 2021, 13, 632. doi: 10.3390/nu13020632.

124. Leeuwendaal, N.K.; Cryan, J.F.; Schellekens. H. Gut peptides and the microbiome: focus on ghrelin. Curr Opin Endocrinol Diabetes Obes 2021, 28, 243-252. doi: 10.1097/MED.0000000000000616.

125. Sanchez, M.; Darimont, C.; Panahi, S.; Drapeau, V.; Marette, A.; Taylor, V.H.; Doré, J.; Tremblay, A. Effects of a DietBased Weight-Reducing Program with Probiotic Supplementation on Satiety Efficiency, Eating Behaviour Traits, and Psychosocial Behaviours in Obese Individuals. Nutrients 2017, 9, 284. doi: 10.3390/nu9030284.

126. Narmaki, E.; Borazjani, M.; Ataie-Jafari, A.; Hariri, N.; Doost, A.H.; Qorbani, M.; Saidpour, A. The combined effects of probiotics and restricted calorie diet on the anthropometric indices, eating behavior, and hormone levels of obese women with food addiction: a randomized clinical trial. Nutr Neurosci 2020, 15, 1-13. doi: 10.1080/1028415X.2020.1826763.

127. Cheng, Y.C.; Liu, J.R. Effect of Lactobacillus rhamnosus GG on Energy Metabolism, Leptin Resistance, and Gut Microbiota in Mice with Diet-Induced Obesity. Nutrients 2020, 12, 2557. doi: 10.3390/nu12092557.

128. Wang, B.; Yu, H.; He, Y.; Wen, L.; Gu, J.; Wang, X.; Miao, X.; Qiu, G.; Wang, H. Effect of soybean insoluble dietary fiber on prevention of obesity in high-fat diet fed mice via regulation of the gut microbiota. Food Funct 2021, 12, 79237937. doi: 10.1039/d1fo00078k.

129. Russell, J.T.; Zhou, Y.; Weinstock, G.M.; Bubier, J.A. The Gut Microbiome and Substance Use Disorder. Front Neurosci 2021, 15, 725500. doi: 10.3389/fnins.2021.725500.

130. Dietert, R.R.; Dietert, J.M. Microbiome First Approaches in Pain Prevention and Management. Am J Biomed Sci Res 2021, 14, 184-192. doi: 10.34297/AJBSR.2021.14.001976.

131. Forouzan, S.; McGrew, K.; Kosten, T.A. Drugs and bugs: Negative affect, psychostimulant use and withdrawal, and the microbiome. Am J Addict 2021, Aug 19. doi: 10.1111/ajad.13210.

132. O'Sullivan, S.J.; Schwaber, J.S. Similarities in alcohol and opioid withdrawal syndromes suggest common negative reinforcement mechanisms involving the interoceptive antireward pathway. Neurosci Biobehav Rev 2021, 125, 355-364. doi: 10.1016/j.neubiorev.2021.02.033. 
133. Xiao, H.W.; Ge, C.; Feng, G.X.; Li, Y.; Luo, D.; Dong, J.L.; Li, H.; Wang, H.; Cui, M.; Fan, S.J. Gut microbiota modulates alcohol withdrawal-induced anxiety in mice. Toxicol Lett 2018, 287, 23-30. doi: 10.1016/j.toxlet.2018.01.021.

134. Zhao, W.; Hu, Y.; Li, C.; Li, N.; Zhu, S.; Tan, X.; Li, M.; Zhang, Y.; Xu, Z.; Ding, Z. et al. Transplantation of fecal microbiota from patients with alcoholism induces anxiety/depression behaviors and decreases brain mGluR1/PKC $\varepsilon$ levels in mouse. Biofactors 2020, 46, 38-54. doi: 10.1002/biof.1567.

135. Rodriguez-Gonzalez, A.; Orio, L. Microbiota and Alcohol Use Disorder: Are Psychobiotics a Novel Therapeutic Strategy? Curr Pharm Des 2020, 26, 2426-2437. doi: 10.2174/1381612826666200122153541.

136. Lucerne, K.E.; Osman, A.; Meckel, K.R.; Kiral,y D.D. Contributions of neuroimmune and gut-brain signaling to vulnerability of developing substance use disorders. Neuropharmacology 2021, 192, 108598. doi: 10.1016/j.neuropharm.2021.108598.

137. Freedman, Z.G.; Kane, J.A.; King, T.S.; Graziane, N.M. The effect of prescribing antibiotics with opioids on the development of opioid use disorder: a national database study. J Addict Dis 2021, 25, 1-13. doi: 10.1080/10550887.2021.1926889.

138. Ezquer, F.; Quintanilla, M.E.; Moya-Flores, F.; Morales, P.; Munita, J.M.; Olivares, B.; Landskron, G.; Hermoso, M.A.; Ezquer, M.; Herrera-Marschitz, M.; Israel, Y. Innate gut microbiota predisposes to high alcohol consumption. Addict Biol 2021, 26, e13018. doi: 10.1111/adb.13018.

139. Carbia, C.; Lannoy, S.; Maurage, P.; López-Caneda, E.; O'Riordan, K.J.; Dinan, T.G.; Cryan, J.F. A biological framework for emotional dysregulation in alcohol misuse: from gut to brain. Mol Psychiatry 2021, 26, 1098-1118. doi: 10.1038/s41380-020-00970-6.

140. García-Cabrerizo, R.; Carbia, C.; O’ Riordan, K.J.; Schellekens, H.; Cryan, J.F. Microbiota-gut-brain axis as a regulator of reward processes. J Neurochem 2021, 157, 1495-1524. doi: 10.1111/jnc.15284.

141. Novelle, M.G. Decoding the Role of Gut-Microbiome in the Food Addiction Paradigm. Int J Environ Res Public Health 2021, 18, 6825. doi: 10.3390/ijerph18136825.

142. Agustí, A.; Campillo, I.; Balzano, T.; Benítez-Páez, A.; López-Almela, I.; Romaní-Pérez, M.; Forteza, J.; Felipo, V.; Avena, N.M.; Sanz, Y. Bacteroides uniformis CECT 7771 Modulates the Brain Reward Response to Reduce Binge Eating and Anxiety-Like Behavior in Rat. Mol Neurobiol 2021, Jul 6. doi: 10.1007/s12035-021-02462-2.

143. Thomaz, A.C.; Iyer, V.; Woodward, T.J.; Hohmann, A.G. Fecal microbiota transplantation and antibiotic treatment attenuate naloxone-precipitated opioid withdrawal in morphine-dependent mice. Exp Neurol 2021, 343, 113787. doi: 10.1016/j.expneurol.2021.113787. 
144. Zawertailo, L.; Attwells, S.; deRuiter, W.K.; Le, T.L.; Dawson, D.; Selby, P. Food Addiction and Tobacco Use Disorder: Common Liability and Shared Mechanisms. Nutrients 2020, 12, 3834. doi:10.3390/nu12123834.

145. Morrow, J.D.; Castaldi, P.J.; Chase, R.P.; Yun, J.H.; Lee, S.; Liu, Y.Y.; Hersh, C.P. Peripheral blood microbial signatures in current and former smokers. Sci Rep 2021, 11, 19875. doi: 10.1038/s41598-021-99238-4.

146. Prakash, A.; Peters, B.A.; Cobbs, E.; Beggs, D.; Choi, H.; Li, H.; Hayes, R.B.; Ahn, J. Tobacco Smoking and the Fecal Microbiome in a Large, Multi-ethnic Cohort. Cancer Epidemiol Biomarkers Prev 2021, 30, 1328-1335. doi: 10.1158/10559965.EPI-20-1417.

147. Kosciolek, T.; Victor, T.A.; Kuplicki, R.; Rossi, M.; Estaki, M.; Ackermann, G.; Tulsa 1000 Investigators.; Knight, R.; Paulus, M.P. Individuals with substance use disorders have a distinct oral microbiome pattern. Brain Behav Immun Health 2021, 15, 100271. doi: 10.1016/j.bbih.2021.100271.

148. Gopinath, D.; Wie, C.C.; Banerjee, M.; Thangavelu, L.; Kumar, R.P.; Nallaswamy, D.; Botelho, M.G.; Johnson, N.W. Compositional profile of mucosal bacteriome of smokers and smokeless tobacco users. Clin Oral Investig 2021, Aug 26. doi: 10.1007/s00784-021-04137-7.

149. He, L.; Zhou, Y.X.; Zhang, Y.; Hang, B.; Chang, H.; Schick, S.F.; Celniker, S.E.; Xia, Y.; Snijders, A.M.; Mao, J.H. Thirdhand cigarette smoke leads to age-dependent and persistent alterations in the cecal microbiome of mice. Microbiologyopen 2021, 10, e1198. doi: 10.1002/mbo3.1198.

150. Kelley, S.T.; Liu, W.; Quintana, P.J.E.; Hoh, E.; Dodder, N.G.; Mahabee-Gittens, E.M.; Padilla, S.; Ogden, S.; Frenzel, S.; Sisk-Hackworth, L.; Matt, G.E. Altered microbiomes in thirdhand smoke-exposed children and their home environments. Pediatr Res 2021, Mar 2:10.1038/s41390-021-01400-1. doi: 10.1038/s41390-021-01400-1.

151. Biedermann, L.; Zeitz, J.; Mwinyi, J.; Sutter-Minder, E.; Rehman, A.; Ott, S.J.; Steurer-Stey, C.; Frei, A.; Frei, P.; Scharl, M. et al. Smoking cessation induces profound changes in the composition of the intestinal microbiota in humans. PLoS One 2013, 8, e59260. doi: 10.1371/journal.pone.0059260.

152. Alberg, A.J.; Carter, C.L.; Carpenter, M.J. Weight gain as an impediment to cigarette smoking cessation: a lingering problem in need of solutions. Prev Med 2007, 44, 296-297. doi: 10.1016/j.ypmed.2007.01.001.

153. Simpson, S.; Kimbrough, A.; Boomhower, B.; McLellan, R.; Hughes, M.; Shankar, K.; de Guglielmo, G.; George, O. Depletion of the Microbiome Alters the Recruitment of Neuronal Ensembles of Oxycodone Intoxication and Withdrawal. eNeuro 2020, 7, ENEURO.0312-19.2020. doi: 10.1523/ENEURO.0312-19.2020. 
154. Lewis, C.B.; Laflin, M.; Gray, D.L. Exercise as Medicine for Older Women. Clin Geriatr Med 2021, 37, 639-650. doi: 10.1016/j.cger.2021.05.009.

155. Nascimento, M.M. Dance, aging, and neuroplasticity: an integrative review. Neurocase 2021, 13, 1-10. doi: 10.1080/13554794.2021.1966047.

156. Carapellotti, A.M.; Stevenson, R.; Doumas, M. The efficacy of dance for improving motor impairments, non-motor symptoms, and quality of life in Parkinson's disease: A systematic review and meta-analysis. PLoS One 2020, 15, e0236820. doi: 10.1371/journal.pone.0236820.

157. Ruiz-Muelle, A.; López-Rodríguez, M.M. Dance for People with Alzheimer's Disease: A Systematic Review. Curr Alzheimer Res 2019, 16, 919-933. doi: 10.2174/1567205016666190725151614.

158. Sakellariou, X.M.; Papafaklis, M.I.; Domouzoglou, E.M.; Katsouras, C.S.; Michalis, L.K.; Naka, K.K. Exercise-mediated adaptations in vascular function and structure: Beneficial effects in coronary artery disease. World J Cardiol 2021, 13, 399-415. doi: 10.4330/wjc.v13.i9.399.

159. Cominato, L.; Franco, R; Damiani, D. Adolescent obesity treatments: news, views, and evidence. Arch Endocrinol Metab 2021, Sep 29:2359-3997000000393. doi: 10.20945/2359-3997000000393.

160. Richards, N.C.; Gouda, H.N.; Durham, J.; Rampatige, R.; Rodney, A.; Whittaker, M. Disability, noncommunicable disease and health information. Bull World Health Organ 2016, 94, 230-232. doi:

http://dx.doi.org/10.2471/BLT.15.156869

161. Lee, M.C.; Hsu. Y.J.; Ho. H.H.; Kuo. Y.W.; Lin. W.Y.; Tsai. S.Y.; Chen. W.L.; Lin. C.L.; Huang. C.C. Effectiveness of human-origin Lactobacillus plantarum PL-02 in improving muscle mass, exercise performance and anti-fatigue. Sci Rep 2021, 11, 19469. doi: 10.1038/s41598-021-98958-x.

162. Agosti, M.; Tandoi, F.; Morlacchi, L.; Bossi, A. Nutritional and metabolic programming during the first thousand days of life. Pediatr Med Chir 2017, 39, 157. doi: 10.4081/pmc.2017.157.

163. Reddy, S.P.; Mbewu, A.D. The Implications of the Developmental Origins of Health and Disease on Public Health Policy and Health Promotion in South Africa. Healthcare (Basel) 2016, 4, 83. doi: 10.3390/healthcare4040083.

164. Barker, D.J. The fetal and infant origins of adult disease. BMJ 1990, 301, 1111. doi: 10.1136/bmj.301.6761.1111.

165. Hanson M, Gluckman P. Developmental origins of noncommunicable disease: population and public health implications. Am J Clin Nutr 2011, 94, 1754S-1758S. doi: 10.3945/ajcn.110.001206. 
166. Adair, L.S. Long-term consequences of nutrition and growth in early childhood and possible preventive interventions. Nestle Nutr Inst Workshop Ser 2014, 78, 111-120. doi: 10.1159/000354949.

167. Raspini, B.; Porri, D.; De Giuseppe, R.; Chieppa, M.; Liso, M.; Cerbo, R.M.; Civardi, E.; Garofoli, F.; Monti, M.C.; Vacca, M.; De Angelis, M.; Cena, H. Prenatal and postnatal determinants in shaping offspring's microbiome in the first 1000 days: study protocol and preliminary results at one month of life. Ital J Pediatr 2020, 46, 45. doi: 10.1186/s13052-020-0794-8.

168. Scher, M.S. "The First Thousand Days" Define a Fetal/Neonatal Neurology Program. Front Pediatr 2021, 9, 683138. doi: 10.3389/fped.2021.683138.

169. Subcomisión DOHaD - SAP “Origen de la Salud y Enfermedad en el Curso de la Vida” - Sociedad Argentina de Pediatría. Concepto de Developmental Origins of Health and Disease: El ambiente en los primeros mil días de vida y su asociación con las enfermedades no transmisibles [Developmental Origins of Health and Disease Concept: The environment in the first 1000 days of life and its association with noncommunicable diseases]. Arch Argent Pediatr 2020, 118, S118-S129. Spanish. doi: 10.5546/aap.2020.S118.

170. Moreno Villares, J.M.; Collado, M.C.; Larqué, E.; Leis Trabazo, R.; Saenz De Pipaón, M.; Moreno Aznar, L.A. Los primeros 1000 días: una oportunidad para reducir la carga de las enfermedades no transmisibles [The first 1000 days: an opportunity to reduce the burden of noncommunicable diseases]. Nutr Hosp 2019, 36, 218-232. Spanish. doi: 10.20960/nh.02453. PMID: 30836758.

171. Chilvers, A. The first 1,000 days. The impact of microbes on health outcomes. J Fam Health 2016, 26, 25-26.

172. Schwartzenberger, S.J. Your Baby's First 1,000 Days: AAP Policy Explained. American Association of Pediatrics. 2018, https://www.healthychildren.org/English/ages-stages/baby/Pages/Babys-First-1000-Days-AAP-Policy-Explained.aspx [published update 1.22.2018] (accessed Oct.6, 2021) 